\title{
Oxygen depletion and nitric oxide stimulate type IV MSHA pilus retraction in Vibrio cholerae via activation of the phosphodiesterase CdpA
}

\author{
Hannah Q. Hughes ${ }^{1}$, Kyle A. Floyd ${ }^{2}$, Sajjad Hossain ${ }^{3}$, Sweta Anantharaman ${ }^{3}$, David T. Kysela ${ }^{4}$, Yuanchen Yu ${ }^{5}$, Michael P. \\ Kappler $^{5}$, Triana N. Dalia ${ }^{1}$, Ram C. Podicheti ${ }^{6}$, Douglas B. Rusch ${ }^{6}$, Yves V. Brun ${ }^{4}$, Stephen C. Jacobson ${ }^{5}$, James B. \\ McKinlay $^{1}$, Fitnat H. Yildiz ${ }^{2}$, Elizabeth M. Boon ${ }^{3}$, and Ankur B. Dalia ${ }^{1, *}$

\begin{abstract}
${ }^{1}$ Department of Biology, Indiana University, Bloomington, IN
2Department of Microbiology and Environmental Toxicology, University of California - Santa Cruz, Santa Cruz, CA

${ }^{3}$ Department of Chemistry and Institute of Chemical Biology \& Drug Discovery, Stony Brook University, Stony Brook, NY

${ }^{4}$ Department of Microbiology, Infectious Diseases, and Immunology, Université de Montréal, Montreal, Quebec, Canada

${ }^{5}$ Department of Chemistry, Indiana University, Bloomington, IN

${ }^{6}$ Center for Genomics and Bioinformatics, Indiana University, Bloomington, IN

*Author for correspondence: ankdalia@indiana.edu
\end{abstract}

\section{ABSTRACT}

Bacteria use surface appendages called type IV pili to perform diverse activities including DNA uptake, twitching motility, and attachment to surfaces. Dynamic extension and retraction of pili is often required for these activities, but the stimuli that regulate these dynamics remain poorly characterized. To study this question, we use the bacterial pathogen Vibrio cholerae, which uses mannose-sensitive hemagglutinin (MSHA) pili to attach to surfaces in aquatic environments as the first step in biofilm formation. Here, we find that $V$. cholerae cells retract MSHA pili and detach from a surface in microaerobic conditions. This response is dependent on the phosphodiesterase CdpA, which decreases intracellular levels of cyclic-di-GMP (c-di-GMP) under microaerobic conditions to induce MSHA pilus retraction. $\mathrm{CdpA}$ contains a putative NO-sensing NosP domain, and we demonstrate that nitric oxide (NO) is necessary and sufficient to stimulate CdpA-dependent detachment. Thus, we hypothesize that microaerobic conditions result in endogenous production of $\mathrm{NO}$ (or an NO-like molecule) in $V$. cholerae. Together, these results describe a regulatory pathway that allows $V$. cholerae to rapidly abort biofilm formation. More broadly, these results show how environmental cues can be integrated into the complex regulatory pathways that control pilus dynamic activity and attachment in bacterial species.

\section{MAIN}

Type IV pili are nearly ubiquitous nanomachines in bacteria $^{1}$. These structures promote a wide variety of functions, including the uptake of DNA for horizontal gene transfer $^{2}$, motility on surfaces ${ }^{3}$, and attachment to surfaces $^{4-6}$. Pili are helical filaments composed of a single repeating protein called the major pilin ${ }^{7}$. Major pilin subunits are dynamically assembled into a helical filament on an inner membrane platform protein through the action of a specific motor ATPase protein. This dynamic process of assembly promotes the extension of the pilus filament from the cell surface. Conversely, through the action of an antagonistic ATPase, pilus filaments are depolymerized and major pilin subunits are recycled into the membrane. The dynamic process of pilus disassembly results in the retraction of these structures ${ }^{8-10}$. The dynamic extension and retraction of pili is crucial for their diverse functions.
Furthermore, this dynamic activity represents one important mechanism that bacteria use to interact with and respond to their environments. However, the mechanisms by which bacteria regulate pilus dynamic activity in response to environmental cues remains poorly characterized. To address this, we examined pilus dynamic activity of the $V$. cholerae type IV MSHA pilus system. MSHA pili are expressed when $V$. cholerae inhabits its aquatic reservoir and are critical for attachment to abiotic surfaces ${ }^{11-13}$. Here, we uncover an environmental condition that stimulates pilus retraction and characterize the molecular mechanism underlying this response.

\section{RESULTS}

MSHA pilus retraction is required for cell detachment from well slides.

MSHA pili are critical for attachment to abiotic surfaces ${ }^{12,13}$ (Fig. S1A), and labelling of MSHA pili ${ }^{5}$ (see Methods) reveals that pilus retraction can promote cell detachment ${ }^{14}$ (Fig. 1A). The physiological cues that regulate pilus dynamic activity in most T4P to influence their downstream functions, however, remain unclear. One condition we identified that induces cell detachment in $V$. cholerae is the incubation of cells in the well of a glass slide. We found that cells progressively detach in a wave that propagates from the center of the well to the edge, leaving only cells on the periphery of the well attached to the surface (Fig. 1B). To further characterize this response, we first developed an assay that allowed us to simultaneously evaluate the detachment of multiple strains in a consistent environment. This assay, henceforth called a "mixed detachment" (MixD) assay, involves mixing equal proportions of two strains that express distinct fluorescent markers, which allows for the subsequent tracking of the detachment of each strain via simple epifluorescence time-lapse microscopy. To validate this approach, we performed a MixD assay of two parent strains expressing either GFP or mCherry (Fig. 1C). As expected, the two parent strains detached at similar rates over the course of $\sim 4$ minutes. Importantly, this assay allows detachment kinetics of a mutant to be directly compared to the parent strain experiencing the same environmental conditions. Thus, we employed MixD assays to identify factors that regulate this detachment response. 
A

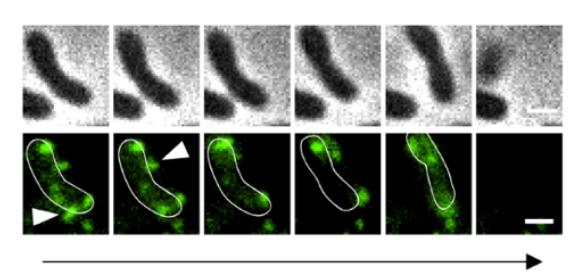

time

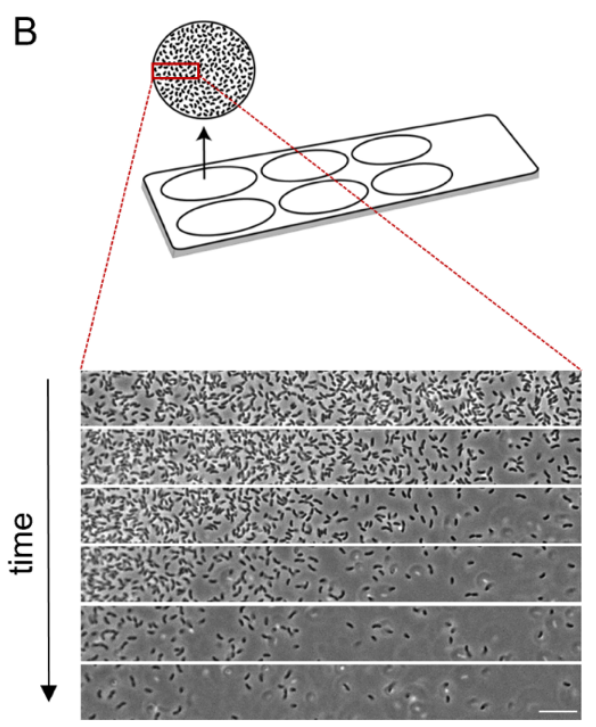

C
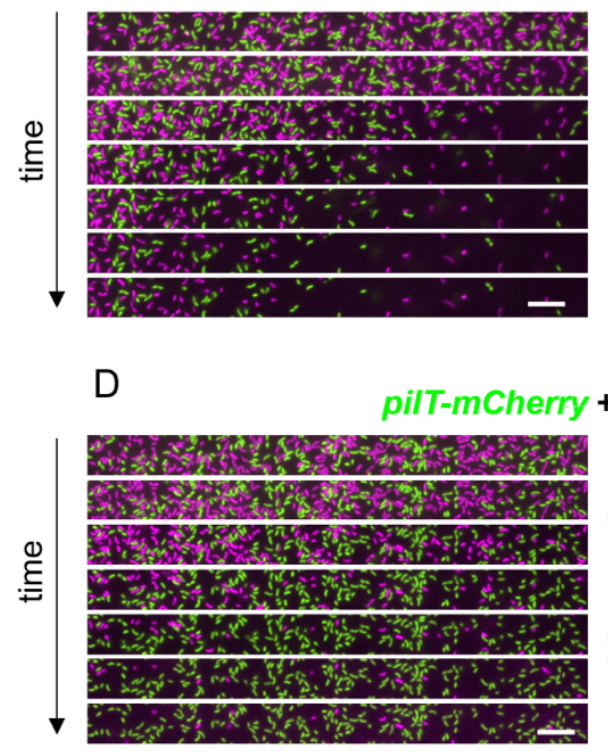

E

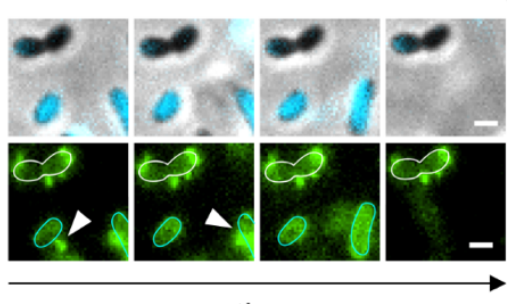

time
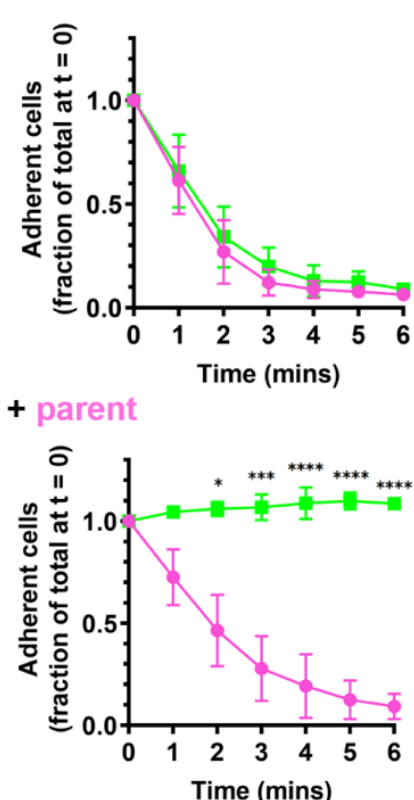

Fig 1: Cells rapidly detach from the surface of a glass well slide in a manner that is dependent on MSHA pilus retraction. (A) Representative montage illustrating that MSHA pilus retraction precedes cell detachment. Phase images (top), showing cell boundaries, and FITC channel (bottom) images, showing AF488-mal labelled MSHA pili. White arrows indicate examples where pili retract prior to detachment. 10 second intervals between frames. Scale bar $=1 \mu \mathrm{m}$. (B) Diagram of experimental setup to observe cell detachment on a glass well slide (top). Representative phase contrast images (bottom) of cell detachment over time. 1-minute interval between frames. Scale bar $=10 \mu \mathrm{m}$. (C-D) Mixed detachment (MixD) assays of the indicated strains. Cells expressed GFP (green) or mCherry (fuchsia) as indicated by the color-coded genotypes. Representative montages of time-lapse imaging (left) with 1-minute intervals between frames. Scale bar $=10 \mu \mathrm{m}$. Quantification of three biological replicates is shown in the line graph (right) and is displayed as the mean \pm the standard deviation (SD). Statistical comparisons were made by one-way ANOVA and post-hoc Holm-Šídák test. ${ }^{*} P<0.05,{ }^{* * *} P<0.001,{ }^{* * *} P<0.0001$. (E) Representative montage of labelled fluorescent MSHA pili in a mixture of a pilT-mCherry strain and a CyPet-expressing parent strain. Phase contrast images with overlaid CyPet fluorescence in cyan (top) distinguish the two strains, and FITC fluorescence images in green (bottom) show AF488-mal labelled pili. Parent cells are outlined in cyan and pilT-mCherry cells are outlined in white. $20 \mathrm{sec}$ intervals between frames. Scale bar $=1 \mu \mathrm{m}$. The PilT-mCherry construct does not exhibit detectable mCherry fluorescence in $\mathbf{D}$ and $\mathbf{E}$.

Because MSHA pilus retraction can promote cell detachment $^{14}$ (Fig. 1A), we first wanted to determine if retraction was required for this detachment response. Deletion of the retraction motor gene pilT is a commonly employed approach for preventing pilus retraction, which results in hyperpiliation of other T4P $\mathrm{P}^{15,16}$. For MSHA pili, however, deletion of pilT results in a dramatic reduction in pilus biogenesis ${ }^{14,17}$ (Fig. S2), for reasons that remain unclear. As an alternative, we took advantage of a natively expressed PilT-mCherry fusion, which we have serendipitously found reduces PilT activity without affecting MSHA pilus biogenesis (Fig. S2). We performed a MixD assay of the parent and PilT-mCherry strains and found that while the parent strain detached, the PilT-mCherry strain remained attached throughout the time-lapse (Fig. 1D). We further verified that when the parent strain detaches, it is preceded by retraction of the MSHA pilus, and the PilTmCherry cells that remain attached retain extended MSHA pili (Fig. 1E), consistent with a lack of retraction in the latter strain background. This observation indicates that MSHA pilus retraction is required for detachment under these conditions.

MSHA pilus retraction and cell detachment are dependent on allosteric regulation of MshE activity by c-di-GMP.

Transitions between sessile and motile lifestyles are often mediated by the secondary messenger cyclic-di-GMP (c-diGMP) ${ }^{18}$. Indeed, c-di-GMP regulates $V$. cholerae motility and biofilm formation in part through control of MSHA dynamic activity ${ }^{14,19}$. Specifically, when c-di-GMP levels are 
elevated through the action of diguanylate cyclases (DGCs), c-di-GMP can bind to the extension motor MshE and allosterically induce pilus extension ${ }^{20}$. Correspondingly, decreased levels of c-di-GMP, which may occur via the activity of phosphodiesterases (PDEs) that cleave c-di-GMP, reduces MshE activity ${ }^{14,20}$ and prevents cell attachment (Fig. S3). Thus, we hypothesized that the detachment phenomenon on slides may be caused by a reduction in intracellular c-di-GMP. If so, we would predict that elevating intracellular c-di-GMP should prevent or delay detachment. To test this, we generated strains where we could ectopically express a diguanylate cyclase, $d c p A^{21}$, to elevate intracellular c-di-GMP levels (PBAD-dcpA). Elevated c-di-GMP can also induce expression of the vps and $r b m \mathrm{loci}^{22}$, which encode Vibrio polysaccharide and biofilm matrix proteins that can confound attachment in these experiments. Therefore, we deleted both loci ( $\Delta$ VC0917-VC0939; here called $\Delta v p s$ ) in the $\mathrm{P}_{\mathrm{BAD}}-d c p A$ background to ensure that attachment in these assays was due to MSHA pili (Fig. S1B). When tested in a MixD assay, we found that $\mathrm{P}_{\mathrm{BAD}}-d c p A \triangle v p s$ showed significantly delayed detachment compared to the parent when $d c p A$ was induced (Fig. 2A). As mentioned above, c-di-GMP is required to allosterically stimulate MshE activity ${ }^{20}$. Previous studies have identified an MshE mutation that maintains activity even in the absence of c-di-GMP (MshE L10A/L54A/L58A, denoted MshE* ${ }^{20}$. If cell detachment is induced by a reduction in the activity of MshE (due to lowered c-di-GMP levels), we hypothesized that an MshE* mutation should delay or prevent cell detachment. Indeed, in a MixD assay, the $M \mathrm{Bs}^{*}$ strain showed a significant reduction in detachment compared to the parent (Fig. 2B).
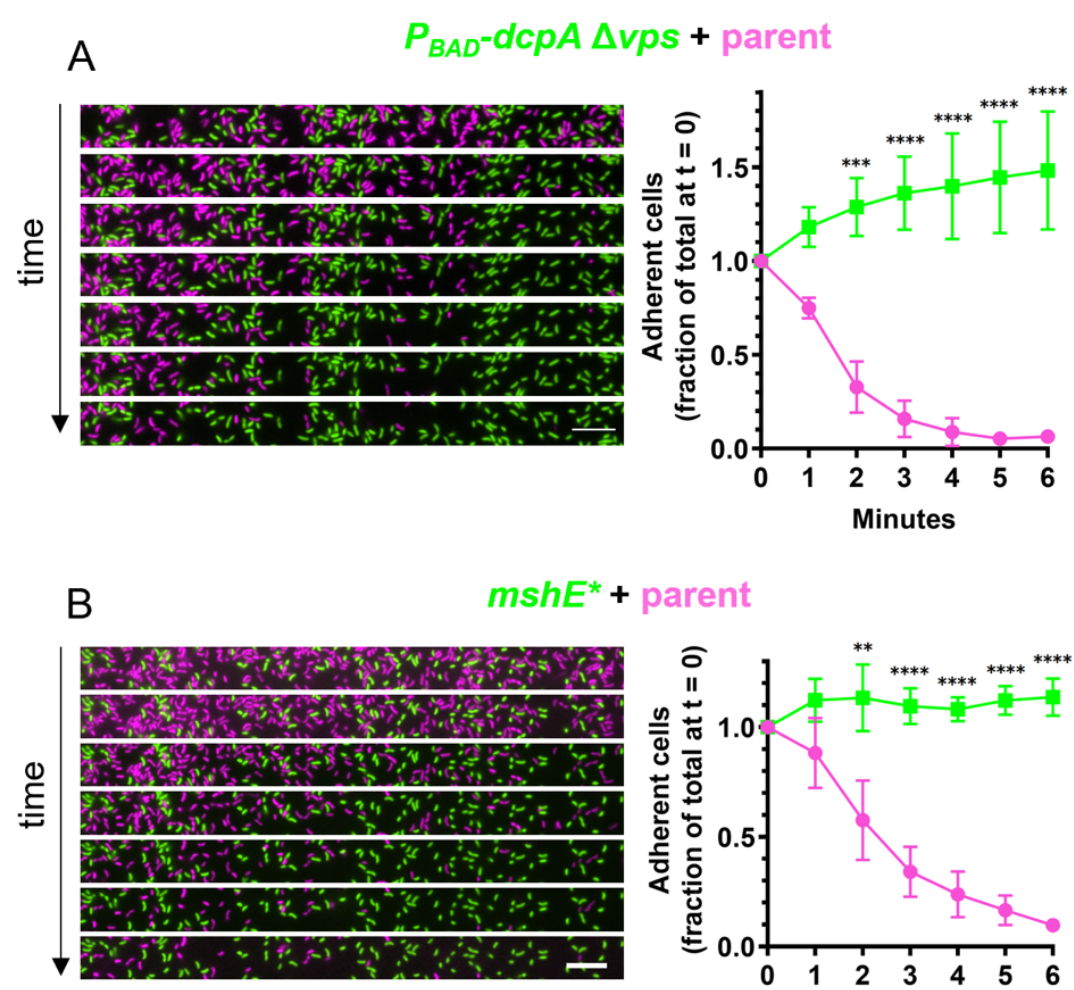

+ parent

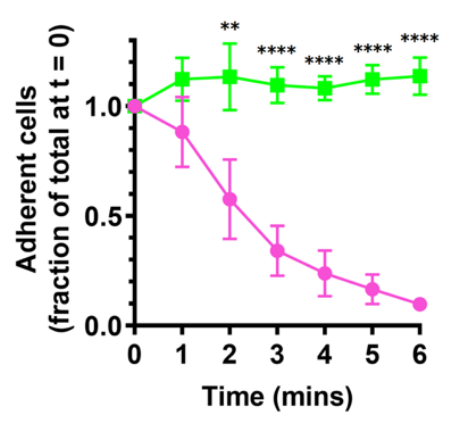

C $P_{B A D}$-dcpA $\triangle v p s$ + parent

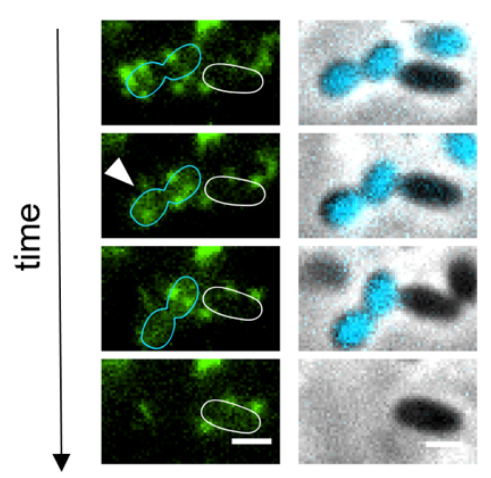

D $m s h E^{*}+$ parent

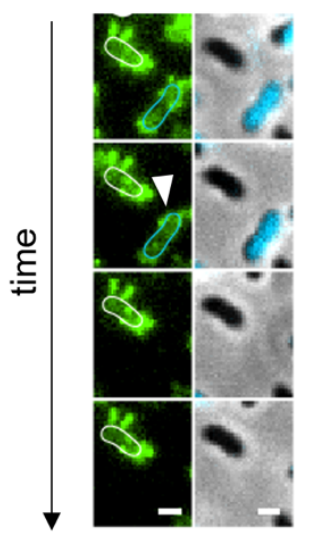

Fig 2: Cell detachment is dependent on allosteric regulation of MshE activity by c-di-GMP. (A) MixD assay of $P_{B A D}-d c p A \Delta v p s$ expressing GFP (green) and a parent strain expressing mCherry (fuschia). $P_{B A D}-d c p A \Delta v p s$ cells were induced with $0.15 \%$ arabinose. Representative montage of time-lapse imaging (left) with 1-minute intervals between frames. Scale bar $=10 \mu \mathrm{m}$. Quantification of three biological replicates is shown in the line graph (right) and is displayed as mean + SD. Statistical comparisons were made by one-way ANOVA and post-hoc Holm-Šídák test. ${ }^{* *} P<0.01,{ }^{* * *} P$ $<0.001$, ${ }^{* * * *} P<0.0001$. (B) MixD assay as in A of $m s h E^{*}$ expressing GFP (green) and a parent strain expressing mCherry (fuschia). (C) Representative montage of time-lapse imaging of cells with AF488-mal labelled MSHA pili. Cells represent a mixture of $P_{B A D}-d c p A \Delta v p s$ cells and CyPet-expressing parent cells. $P_{B A D}$-dcpA $\triangle v p s$ cells were induced with $0.15 \%$ arabinose as in $\mathbf{A}$. Phase contrast images with overlaid CyPet fluorescence in cyan (right) distinguish the mixed strains, and FITC fluorescence images in green (left) show labelled pili. Parent cells are outlined in cyan and $P_{B A D}-d c p A \triangle v p s$ cells are outlined in white. White arrows indicate clear examples where pilus retraction precedes cell detachment. $20 \mathrm{sec}$ intervals between frames. Scale bar $=1 \mu \mathrm{m}$. (D) Representative montage of time-lapse imaging of cells where pili are fluorescently labelled as in C. Cells represent a mixture of $m s h E^{*}$ cells and parent cells expressing CFP. Parent cells are outlined in cyan and $m s h E^{*}$ cells are outlined in white. 

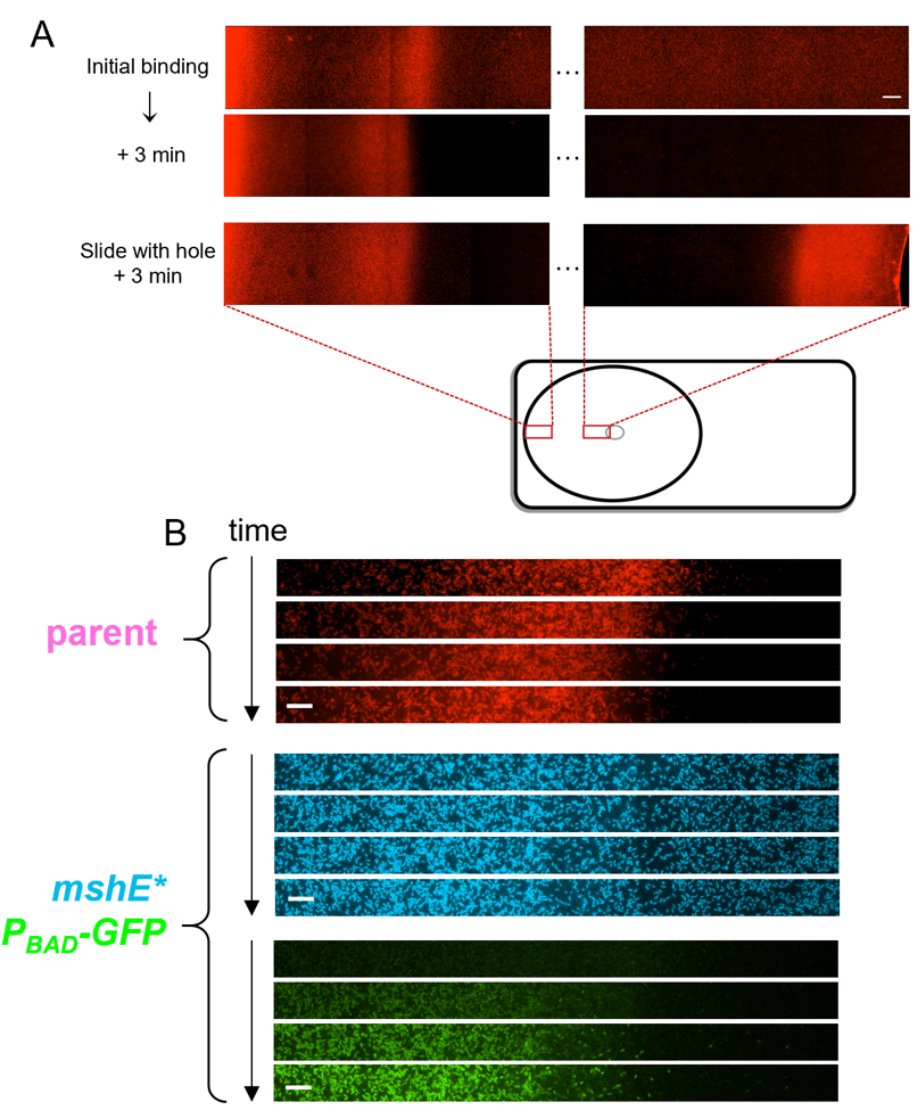

Consistent with MshE* bypassing c-di-GMP-dependent regulation, attachment of the $\mathrm{MshE}^{*}$ strain is not altered even when the PDE cdgJ is overexpressed in this background (Fig S3). Also, direct labeling of pili in the PBAD$\operatorname{dcpA} \Delta v p s$ and $\mathrm{MshE}^{*}$ strains demonstrated that cells maintained extended MSHA pili, which is consistent with a lack of pilus retraction in these backgrounds (Fig 2C, D). Together, these results suggest that cell detachment on slides is caused by MSHA pilus retraction in response to allosteric regulation of MshE by c-di-GMP.

\section{Cell detachment occurs under microaerobic conditions.}

Next, we sought to define the environmental stimulus that drives this detachment response. Because well slides were covered with an air-impermeable glass coverslip, the edge of the well is the only place where cells can access $\mathrm{O}_{2}$ for cellular respiration. Thus, we hypothesized that $\mathrm{O}_{2}$ depletion in the center of the well, which likely occurs as cells respire, is an environmental cue that induces MSHA pilus retraction. To test this, we drilled holes into slides such that the centers of the wells were opened to air. Under these conditions, cells detached as seen previously, except that in the center of the well, cells stayed bound around the hole (Fig. 3A). This result is consistent with oxygen availability contributing to persistent cell attachment.

To determine if oxygen depletion correlates with cell detachment, we generated a bioreporter strain that can indirectly indicate oxygen availability. This bioreporter operates on the basis of oxygen being required for the maturation of the GFP chromophore ${ }^{23}$. Specifically, to make an $\mathrm{O}_{2}$ reporter we generated a strain in the $\mathrm{MshE}^{*}$ background where CyPet (a cyan fluorescent protein
Fig 3: $\mathrm{O}_{2}$ depletion induces cell detachment. (A) Cell attachment was monitored in well slides by fluorescence microscopy with an mCherry expressing parent strain. Wells either lacked (top and middle) or contained (bottom) a hole in the center of the slide to serve as an air source. Five fields of view are omitted between the edge (left) and center (right) of the well. Scale bar = $50 \mu \mathrm{m}$. (B) Representative montage of timelapse imaging of a mixed culture of an mCherry expressing parent and a CyPet expressing $m s h E^{*}$ strain. The $m s h E^{*}$ strain also contains a $P_{B A D}$-gfp construct, which serves as a bioreporter for $\mathrm{O}_{2}$ in this experiment. Arabinose was added to the mixed culture immediately before imaging. Montages are shown for each fluorescent channel separately with 25-min intervals between frames. Scale bar $=10 \mu \mathrm{m}$. derivative) was constitutively expressed and GFP expression was tightly regulated via an arabinose-inducible promoter $\left(\mathrm{P}_{\mathrm{BAD}}-g f p\right)$. The $\mathrm{MshE}^{*}$ mutation prevents detachment in this experimental setup (as in Fig. 2C), the constitutive expression of CyPet allows for easy cell tracking, and the addition of arabinose allows for the de novo production of GFP. To track the kinetics and boundaries of cell detachment, we mixed this $\mathrm{O}_{2}$ reporter strain with a parent strain constitutively expressing mCherry. In this experiment, arabinose was added immediately before strains were placed on well slides, thereby inducing expression of GFP protein in all CyPet labeled cells. However, GFP would only mature into its fluorescent form where sufficient oxygen was present. This process was monitored by epifluorescence time-lapse microscopy. As expected, the parent strain rapidly detached while the MshE* $^{*}$ strain remained attached throughout the time-lapse. Notably, only cells at the edge of the well exhibited GFP fluorescence (Fig. 3B), which is consistent with a lack of GFP maturation in the center of the well due to oxygen depletion. Interestingly, the boundary of GFP fluorescence was similar to the boundary of cell attachment observed in the parent strain (Fig. 3B). Although not necessarily expected, this result indicated that the threshold of oxygen required for cell attachment is similar to the threshold required for GFP maturation. Together, these results strongly suggest that $\mathrm{O}_{2}$ depletion is an environmental cue that induces MSHA pilus retraction and subsequent cell detachment.

Thus far, our data suggest that $\mathrm{O}_{2}$ depletion induces MSHA pilus retraction in a manner that depends on a decrease in cellular c-di-GMP. We, therefore, hypothesized that $V$. 
cholerae carries a PDE that, during $\mathrm{O}_{2}$ depletion, decreases c-di-GMP levels, triggering MSHA pilus retraction and cell detachment. We would expect a mutant lacking this putative PDE to exhibit enhanced adherence under microaerobic conditions (akin to the MshE* mutant). To test this hypothesis, we first established conditions that would allow us to study the effect of oxygen depletion in a larger culture format. To accomplish this, we allowed cells to bind to the sides of either open, rolling glass tubes (aerobic; "+air"), or sealed, static argon-flushed glass tubes (microaerobic; "-air") (see Methods). We confirmed that these culture conditions recapitulated the binding phenotypes seen in the MixD assays, where the parent strain bound poorly under microaerobic conditions and the

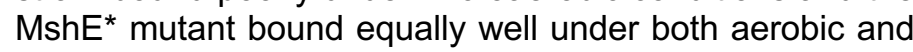
microaerobic conditions (Fig. S4A). We also directly measured oxygen levels to confirm that our culture conditions generated aerobic and microaerobic environments, as expected (Fig. S4B, C).

\section{Cell detachment requires the phosphodiesterase $\mathrm{CdpA}$.}

We then carried out a genetic selection to isolate transposon mutants that exhibited enhanced adherence under microaerobic conditions, thereby identifying factors, like the hypothesized PDE, that might be required to stimulate cell detachment. Following the genetic selection, we isolated 10 colonies and sequenced the Tn-genomic junction in each. All mutants contained Tn insertions (9 distinct mutations) in cdpA (VC0130) (Fig. S5A). CdpA is a functional PDE that contains a NosP sensory domain ${ }^{24,25}$. In a MixD assay, the $\triangle c d p A$ mutant exhibited significantly delayed detachment compared to the parental strain (Fig. S5B). Importantly, this phenotype could be complemented in trans with a single copy of $c d p A$ integrated at an ectopic location under the control of its native promoter $(\triangle c d p A$ $\triangle / a c Z:: c d p A^{\mathrm{WT}}$ ) (Fig. 4A). These results confirm that CdpA plays an important role in cell detachment under microaerobic conditions.

Because CdpA is a PDE, we hypothesized that it reduced c-di-GMP under microaerobic conditions to promote MSHA pilus retraction and subsequent cell detachment. To test this, we first mutated the $E A L$ domain required for $P D E$ activity in $c d p A$ ( $c d p A$ has ECL instead of the canonical $\mathrm{EAL}$ within this domain). In MixD assays, the $\triangle c d p A$ $\triangle / a c Z:: c d p A^{\text {ECLàAA }}$ strain phenocopied the $\triangle c d p A$ mutant (Fig. 4B), indicating that the PDE activity of CdpA plays a critical role in promoting cell detachment. Consistent with this result, we found that intracellular levels of c-di-GMP (measured by LC-MS/MS) were reduced under the microaerobic conditions that stimulate cell detachment in a CdpA-dependent manner (Fig. 4C, S4A).

Based on the data described above, CdpA likely degrades c-di-GMP specifically under microaerobic conditions. What remains unclear is the mechanism by which $\mathrm{CdpA}$ activity is stimulated. One possibility is that upon a decrease in oxygen, CdpA protein levels are increased. To test this hypothesis, we generated a functional $c d p A-3 x F L A G$ strain (Fig. S5C) and assessed protein levels by western blot. This revealed that there was a slight, albeit not significant, increase in total CdpA levels when cells were incubated microaerobically (Fig. 4D). We did find that the intensity of a high molecular weight CdpA band is increased in western blots when cells are incubated microaerobically (Fig. 4D). This band may represent an active CdpA complex. Regardless, because total CdpA levels are not dramatically altered in these experiments, we hypothesized that $\mathrm{CdpA}$ activity is likely modulated via a post-translational mechanism.

NO is necessary and sufficient to promote MSHA pilus retraction and cell detachment in a CdpA-dependent manner.

Other oxygen-responsive PDEs and DGCs have been characterized, often sensing oxygen through a hemebinding PAS or globin domain ${ }^{26-29}$. CdpA lacks these domains, and instead encodes a NosP domain, which has recently been shown to bind heme in a manner that alters its PDE activity ${ }^{25}$. NosP domains have previously been implicated in sensing $\mathrm{NO}^{30}$, and bacterial $\mathrm{NO}$ production generally occurs under microaerobic conditions ${ }^{31,32}$. Thus, we hypothesized that microaerobic conditions may indirectly induce MSHA retraction by promoting NO production, which induces CdpA activity. Therefore, we tested whether NO was necessary and sufficient to induce CdpA-dependent detachment. To determine if NO was necessary for detachment, we incubated cells on sides with the NO scavenger 2-phenyl-4,4,5,5,tetramethylimidazoline-1-oxyl 3-oxide (PTIO). In the presence of PTIO, parent cells remained attached to the surface in a manner that resembled the $\triangle c d p A$ mutant (Fig. 5A). To exclude the possibility that PTIO was nonspecifically scavenging reactive oxygen species (ROS) ${ }^{33}$, we also assessed the impact of the ROS-specific scavenger Tiron. Tiron did not inhibit detachment of the parent strain, suggesting that $\mathrm{PTIO}$ inhibits cell detachment by specifically scavenging $\mathrm{NO}$, or a related molecule (Fig. $\mathbf{5 A}$ ). To test if NO was sufficient to induce detachment, we incubated cells with the NO donor diethylamine-NONOate (DEA-NONOate) and assessed cell attachment under aerobic conditions. We found that parent cells attached poorly in the presence of DEA-NONOate, whereas attachment of the $\triangle c d p A$ mutant was unaffected (Fig. 5B). Furthermore, incubation with DEA-NONOate resulted in MSHA pilus retraction in a CdpA-dependent manner (Fig. 5C). Together, these observations are consistent with $\mathrm{NO}$ being necessary and sufficient to induce MSHA pilus retraction via stimulating $\mathrm{CdpA}$ activity.

Next, we wanted to determine how widespread this CdpAdependent activity may be. Phylogenetic analysis revealed that $\mathrm{CdpA}$ is largely conserved among the Vibrionaceae and is also prevalent in Aliivibrio species (Fig. S6, S7). Based on sequence similarity and presence within the Vibrio and Allivibrio, we conclude that these are homologs with a conserved functional role. Furthermore, we found $c d p A$ homologs in phylogenetically distant species (e.g., Clostridium and Bacillus) (Fig. 4E, S8, Table S1). Thus, it is tempting to speculate that $\mathrm{CdpA}$ may be a widely conserved, horizontally transferred NO-responsive PDE.

Above, our data suggest that $\mathrm{CdpA}$ may be posttranslationally regulated. Because the heme-bound NosP 
bioRxiv preprint doi: https://doi.org/10.1101/2021.04.20.440694; this version posted April 20, 2021. The copyright holder for this preprint (which was not certified by peer review) is the author/funder. All rights reserved. No reuse allowed without permission.

A

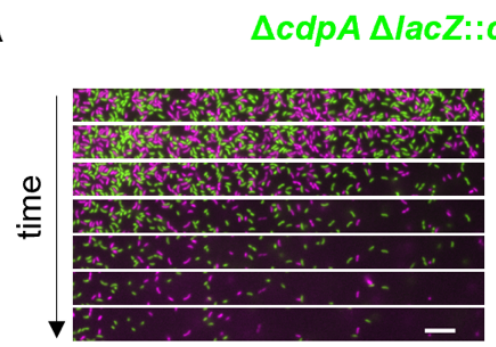

$d p A+$ parent

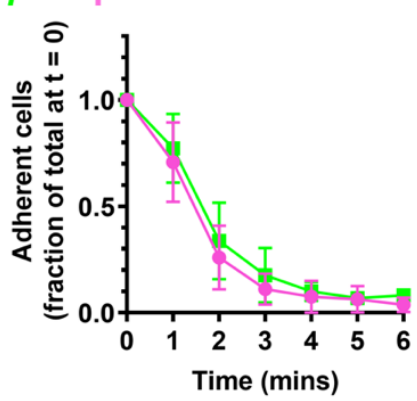

B

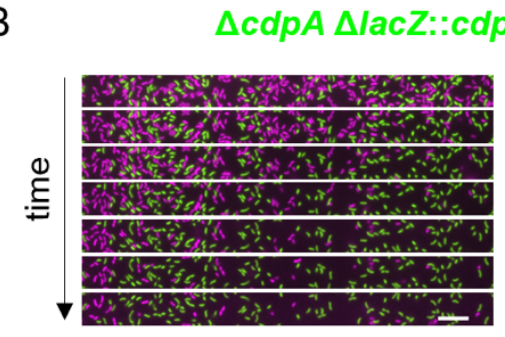

parent

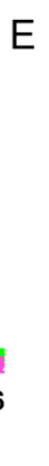

A Arc Methanococcus
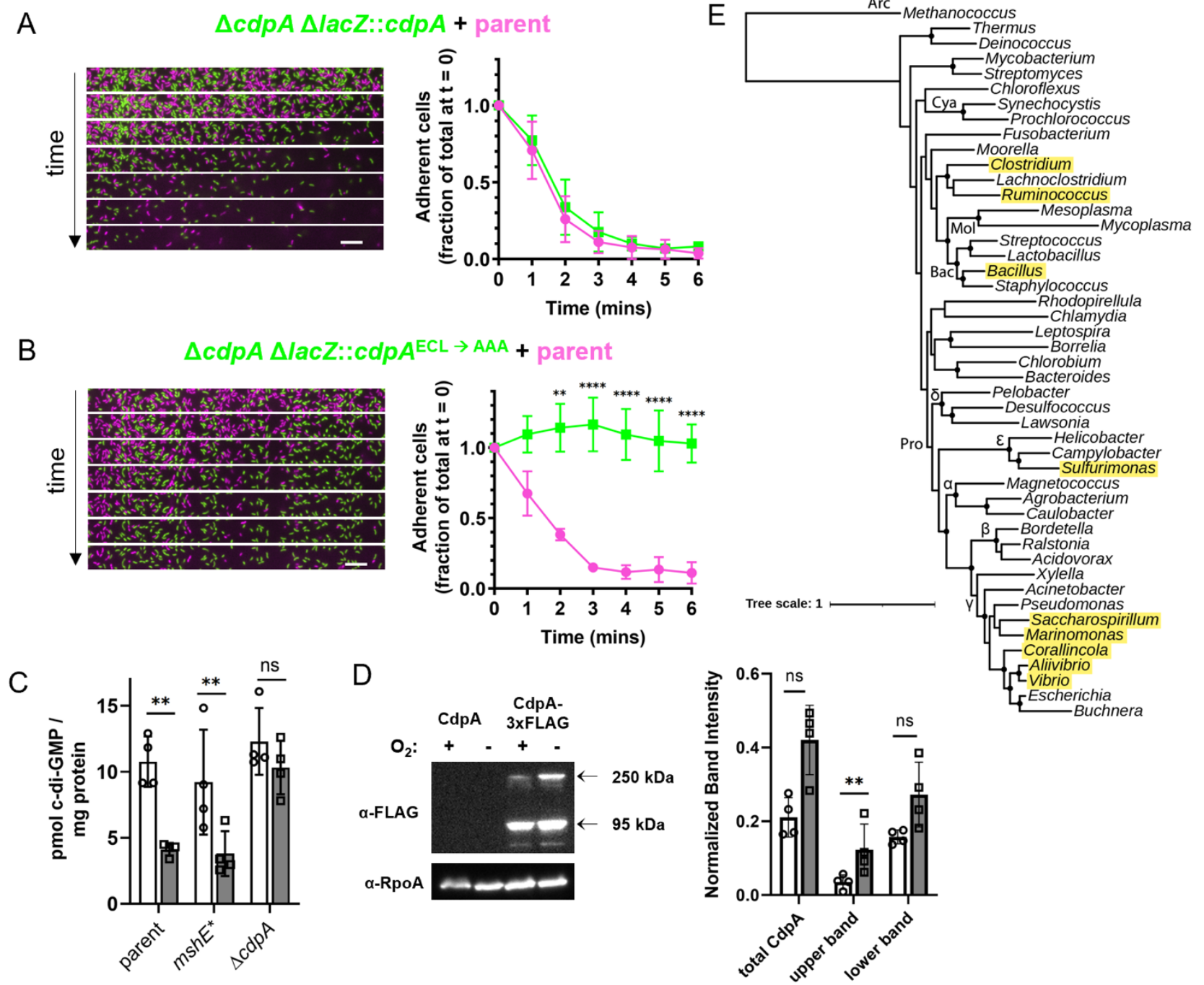

Fig 4: CdpA promotes cell detachment in microaerobic conditions via its PDE activity. (A-B) MixD assays of the indicated strains. Cells expressed GFP (green) or mCherry (fuchsia) as indicated by the color-coded genotypes. Complemented strains are denoted by " $\triangle l a c Z:: c d p A$ ", indicating that a copy of $c d p A$ along with its native promoter were introduced at an ectopic site on the chromosome. Representative montage of time-lapse imaging (left) with 1-minute intervals between frames. Scale bar = $10 \mu \mathrm{m}$. Quantification of three biological replicates is shown in each line graph (right). (C) Quantification of intracellular c-diGMP concentrations in the indicated strains. Data are from four independent biological replicates. Open bars represent samples from aerobic cells while shaded bars indicate samples from microaerobic cells. (D) Representative western blot (right) and quantification (left) measure CdpA protein levels under aerobic and microaerobic conditions. Open bars represent aerobic cells and shaded bars represent microaerobic cells. Band intensities were normalized to the RpoA loading control (visualized on a separate blot). Data are from four independent experiments. Statistical comparisons were made on log-transformed data. (E) Conservation of CdpA across bacterial species. Estimated maximum likelihood phylogeny of the indicated microbes based on a concatenated alignment of 36 conserved proteins identified from whole genome sequences. Genera with members that contain a CdpA homolog are highlighted in yellow. For a complete list of species that contain a CdpA homolog see Table S1. Major taxa are labeled along their nodes. Pro: Proteobacteria (Greek letters indicate subdivisions); Bac: Bacilli; Mol: Mollicutes; Cya: Cyanobacteria; Arc: Archaea. Scale bar indicates distance. All graphs display mean \pm SD. Statistical comparisons were made by one-way ANOVA and post-hoc Holm-Šídák test. ${ }^{*} P<0.05,{ }^{* \star} P<0.01,{ }^{* \star * \star} P<0.0001$.

domain of $\mathrm{CdpA}$ is implicated in directly reacting with NO, we also assessed the impact of NO on the PDE activity of purified heme-bound CdpA. This assay showed that there was a slight, but inconsistent increase in PDE activity for Fe"l-NO CdpA compared to CdpA bound to heme alone (Fig. 5D). This discrepancy in NO-mediated activity compared to the in vivo data may be due to limitations of the in vitro setup. While the heme moiety used for this experiment (heme b) matches what was observed natively bound to other NosP-containing proteins purified from $E$. coli $i^{30}, \mathrm{CdpA}$ may bind a different heme moiety in vivo. Alternatively, there may be an unidentified cofactor required for CdpA activity which is present in vivo but lacking in our in vitro assays. In support of this hypothesis, we show that CdpA PDE activity is very poor in vitro (requires overnight incubations) (Fig. 5D), despite the fact that it exerts its effect in vivo within a matter of minutes (Fig. 4). 
bioRxiv preprint doi: https://doi.org/10.1101/2021.04.20.440694; this version posted April 20, 2021. The copyright holder for this preprint (which was not certified by peer review) is the author/funder. All rights reserved. No reuse allowed without permission.

A major tenet of our model is that $V$. cholerae endogenously generates NO under microaerobic conditions to stimulate CdpA activity. An important caveat to this conclusion, however, is that $V$. cholerae lacks the canonical denitrification or dissimilatory nitrate reduction to ammonia
(DNRA) pathways that allow many bacterial species to generate NO. $V$. cholerae encodes a nitrate reductase (in the Nap operon) that converts nitrate to nitrite, but it lacks homologs of other denitrification or DNRA enzymes 34,35 . Although $V$. cholerae encounters NO during infection ${ }^{36-38}$, it

\section{A}

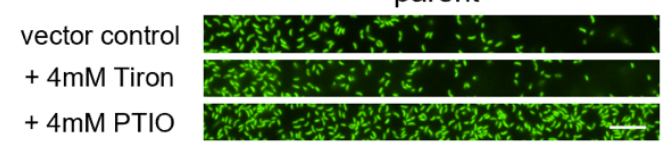

B

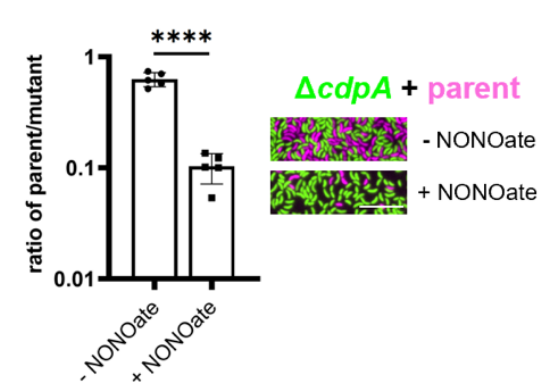

D

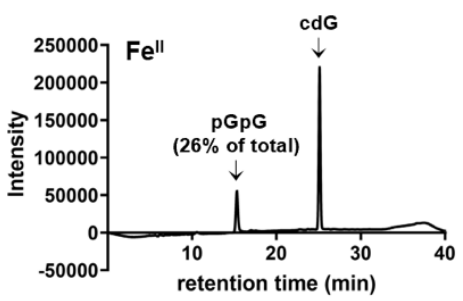

E

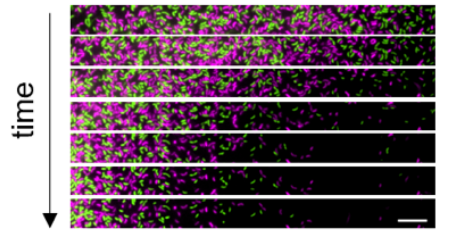

$\Delta N a p+$ parent

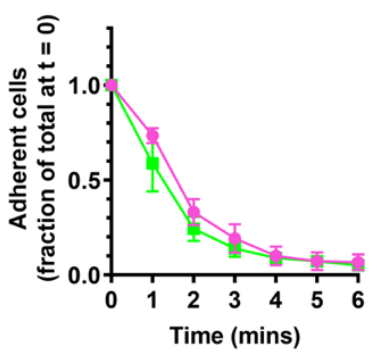

C

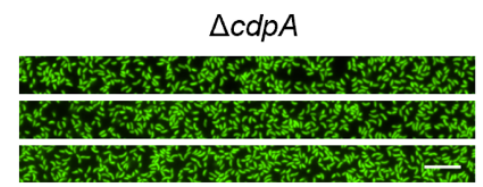

$\Delta c d p A+$ parent
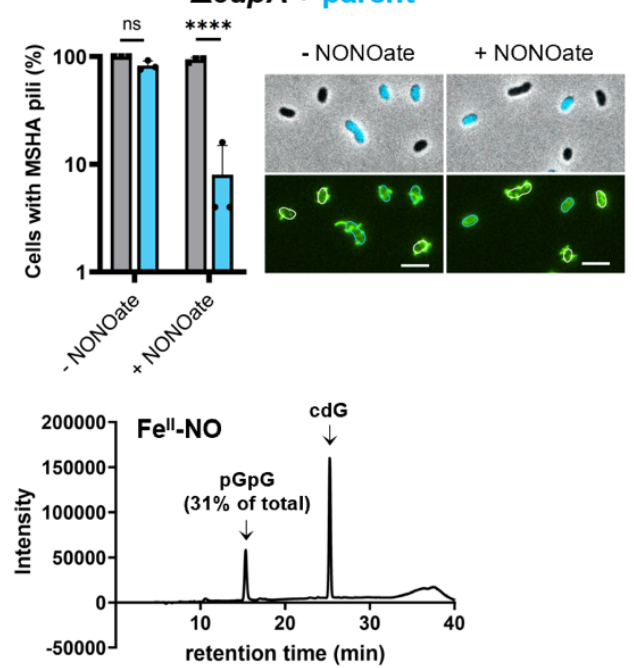

$\mathrm{F}$

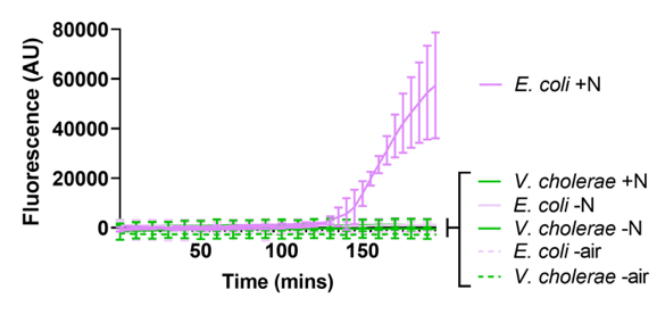

Fig 5: Nitric oxide stimulates detachment in a CdpA-dependent manner. (A) Representative detachment images of GFPexpressing parent or $\triangle c d p A$ strains after incubation with Tiron $(4 \mathrm{mM})$, PTIO (4 mM), or DMSO as a vector control. Scale bar $=10 \mu \mathrm{m}$. (B) Quantification (left) of initial attachment for a 1:1 mixture of the GFP-expressing parent (green) and mCherryexpressing $\Delta c d p A$ mutant (fuchsia) when incubated in the presence or absence of $200 \mu \mathrm{M}$ DEA-NONOate, as indicated. Ratio is determined by dividing the number of attached parent cells (green) by the number of attached $\triangle c d p A$ mutant cells (fuchsia) as depicted in the representative image on the right. Data are from five independent experiments with at least 270 cells analyzed per replicate. Statistical comparison made by t-test. Scale bar $=10 \mu \mathrm{m}$. (C) Quantification (left) of parent (blue) or $\Delta c d p A$ (gray) piliation after incubation in the presence or absence of $200 \mu \mathrm{M}$ DEA-NONOate. Fraction is determined by dividing number of cells with pili by the total number of cells counted for that strain for that condition. Data are from three independent experiments with at least 50 cells analyzed per replicate, per condition. Representative images (right) of cells with AF488-mal labelled MSHA pili. Cells represent a mixture of $\triangle c d p A$ cells and CyPet-expressing parent cells. Phase contrast images with overlaid CyPet fluorescence in cyan (top) distinguish the mixed strains, and FITC fluorescence images in green (bottom) show labelled pili. Parent cells are outlined in cyan and $\triangle c d p A$ cells are outlined in white. Scale bar $=3 \mu \mathrm{m}$. (D) Representative HPLC analysis of purified CdpA PDE activity, indicating the amount of c-di-GMP converted into pGpG. Reactions containing c-di-GMP and purified CdpA with Fe" heme (left) or purified CdpA with Fe"l-NO (right) were incubated for $24 \mathrm{hr}$ at room temperature. (E) MixD assays of parent and $\triangle N a p$ strains. Cells expressed GFP (green) or mCherry (fuchsia) as indicated by the color-coded genotypes. Representative montage of time-lapse imaging (left) with 1-minute intervals between frames. Scale bar $=10 \mu \mathrm{m}$. Quantification of three biological replicates is shown in the line graph (right). (F) DAR 4M-AM measurement of NO production in cells. Mean \pm SD of fluorescence values for three independent, biological replicates are graphed. Dashed lines indicate samples incubated microaerobically. +/-N indicates incubation with or without $20 \mathrm{mM}$ nitrate. The "-air" condition denotes the microaerobic conditions that stimulate $V$. cholerae detachment. Data in panels $\mathbf{B}$ and $\mathbf{D}-\mathbf{F}$ display the mean \pm SD. Statistical comparisons were made by one-way ANOVA and post-hoc Holm-Šídák test. ns $=$ not significant, ${ }^{* \star \star \star} P<0.0001$. 
is not thought to generate NO endogenously. MixD analysis of a $\Delta$ Nap mutant ${ }^{39}$ (Fig. S9A) was indistinguishable from the parent (Fig. 5E), suggesting that nitrate reductase activity is not required to generate a molecular cue for cell detachment. Thus, if NO is being generated, it must be through a pathway previously uncharacterized in $V$. cholerae.

To test whether $V$. cholerae was actually generating NO, we incubated cells with diaminorhodamine-4M acetoxymethyl ester (DAR-4M AM), an NO-specific fluorescent probe. Using DAR-4M AM, we readily measured NO produced by DEA-NONOate (Fig. S9B) and E. coli, which has an intact DNRA pathway, but were unable to detect NO production from $V$. cholerae, even when cells were incubated under the microaerobic conditions that induce cell detachment (Fig 5F). Importantly, NO was still detected by DAR-4M AM when cells were mixed with DEANONOate, albeit to a reduced level. These data suggest that cells may slightly decrease the threshold for NO detection by DAR-4M AM by acting as an NO "sponge". Thus, it remains feasible that concentrations of NO lower than our limit of detection in the presence of cells (i.e., 40 $\mu \mathrm{M}$ DEA-NONOate) are generated in $V$. cholerae. Furthermore, there is evidence that extracellular NO may not equilibrate with cytoplasmic levels ${ }^{40}$, allowing for the possibility that $\mathrm{NO}$ generated endogenously by $V$. cholerae may be at levels too low to be measured by this technique. Alternatively, V. cholerae may be generating a distinct, NOlike molecule that promotes cell detachment under microaerobic conditions. This could explain why NO was not able to strongly stimulate CdpA PDE activity in vitro (Fig. 5D) and why NO was not detected by DAR-4M AM in cells incubated microaerobically (Fig. 5F). Defining the precise environmental signals and cofactors required to stimulate CdpA PDE activity will be a focus of future work. While our data indicate that NO is sufficient to stimulate cell detachment in V. cholerae (Fig. 5B), the means by which
$\mathrm{NO}$ (or an NO-like molecule) is endogenously generated remains unclear.

\section{DISCUSSION}

While the frequency and timing of pilus extension and retraction are crucial to their function, many questions remain about how pilus dynamics are regulated. Some progress has been made on this front, including characterization of protein regulators that impact extension ${ }^{41-43}$ and the impact of spatial organization of the extension and retraction motors ${ }^{44-46}$. Our study highlights another mode of regulation for pilus dynamic activity, wherein environmental regulatory cues rapidly induce pilus retraction through modulation of a secondary messenger (c-di-GMP) that is required for pilus biogenesis (Fig. 6).

CdpA is only one of at least 62 enzymes that contribute to c-di-GMP production and/or degradation in V. cholerae ${ }^{47}$. These diverse DGCs and PDEs are believed to respond to distinct signals/cues, thus allowing cells to modulate c-diGMP under different environmental conditions ${ }^{18}$. While inducing signals have been determined for some of these enzymes $^{48-50}$, the complex regulatory interplay between them is largely uncharacterized and many of the environmental cues required to stimulate their activities remain unclear. Here, we uncover that $\mathrm{CdpA}$ responds to NO (and/or an NO-like signal) that is endogenously generated under microaerobic conditions to reduce intracellular c-di-GMP. One outcome for this response is the retraction of MSHA pili, which results in cell detachment.

MSHA pili are principally required by $V$. cholerae to form biofilms in the aquatic environment. Retraction of MSHA pili under microaerobic conditions and/or in the presence of NO, however, may also be biologically relevant when this facultative pathogen infects its human host. Expression of MSHA pili during infection is known to attenuate $V$. cholerae due to the propensity of these appendages to bind
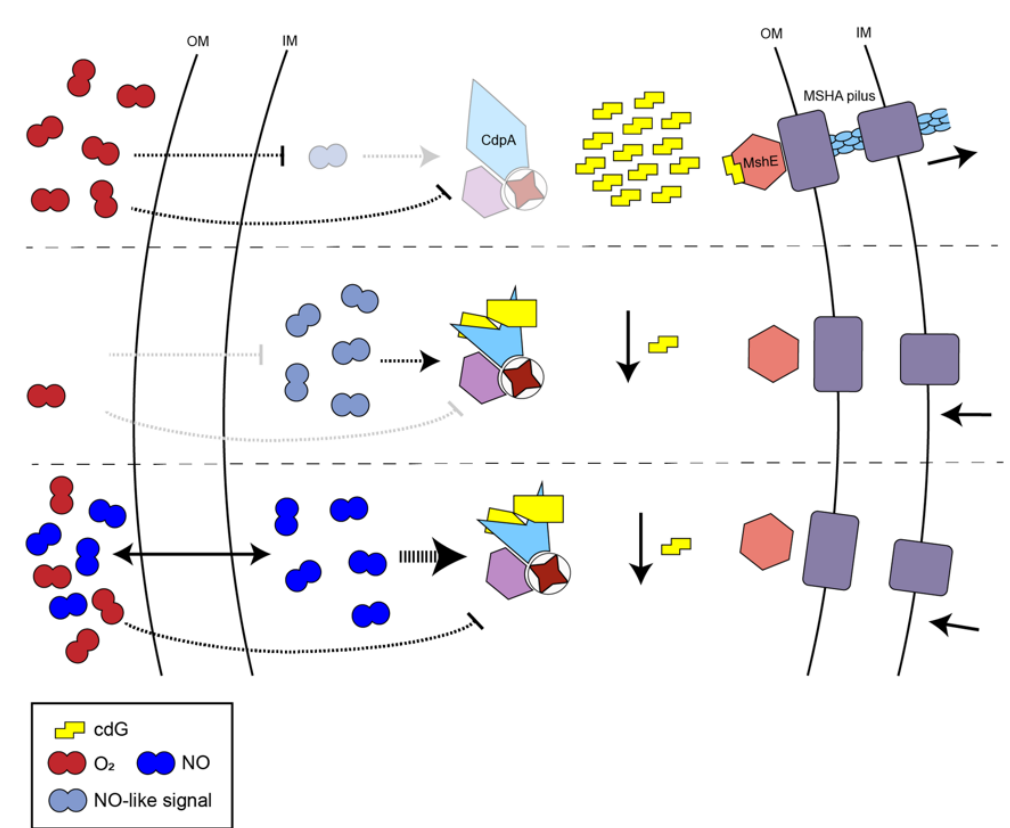

Fig 6: Proposed model for CdpA-dependent induction of MSHA pilus retraction. Under aerobic conditions (top), high oxygen levels inhibit the production of an endogenous NO-like molecule. As a result, CdpA remains inactive, and intracellular c-di-GMP levels stay elevated. This stimulates MshE activity, which causes extension of the MSHA pili and promotes attachment of cells to a surface. Under microaerobic conditions (middle), cells endogenously generate low quantities of $\mathrm{NO}$ (or an NO-like signal) through an unknown mechanism. Low oxygen and the NO-like signal, along with a putative cofactor (depicted in lavender), stimulate the PDE activity of CdpA. This decreases the intracellular concentration of c-di-GMP, prompting the retraction of MSHA pili and detachment of cells from the surface. Exogenously added NO (bottom) is sufficient to stimulate CdpA activity even under aerobic conditions (possibly because stimulation by $\mathrm{NO}$ is stronger than inhibition by $\mathrm{O}_{2}$ ), which results in decreased c-di-GMP, retraction of MSHA pili, and cell detachment. 
secretory $\lg A$ in the gut, which promotes their clearance from the small intestine ${ }^{51}$. Indeed, the expression of the MSHA locus is downregulated during infection ${ }^{51,52}$. As the small intestine is a low-oxygen, high-NO environment ${ }^{53,54}$, we speculate that these cues could represent an important trigger to induce rapid MSHA pilus retraction, contributing to $V$. cholerae's ability to evade the host innate immune response during infection.

\section{ACKNOWLEDGEMENTS}

We would like to thank Clay Fuqua, Julia van Kessel, Tuli Mukhophadyay, and Ilana Heckler for helpful discussions. This work was supported in part by grants R35GM128674 (to ABD), R01Al102584 (to FHY), GM118894 (to EMB), and R01GM113121 (to SCJ) from the National Institutes of Health. YVB is supported by a Canada 150 Research Chair from the Canadian Institutes of Health Research.

\section{METHODS}

Bacterial strains and culture conditions

Vibrio cholerae E7946 was used throughout the study. Cultures were routinely grown in LB broth (Miller) and plated on LB agar at $30^{\circ} \mathrm{C}$. Descriptions of all strains used in this study are found in Supplemental Table 2. Where appropriate, media were supplemented with kanamycin $50 \mu \mathrm{g} / \mathrm{mL}$, trimethoprim $10 \mu \mathrm{g} / \mathrm{mL}$, spectinomycin $200 \mu \mathrm{g} / \mathrm{mL}$, chloramphenicol $1 \mu \mathrm{g} / \mathrm{mL}$, carbenicillin $100 \mu \mathrm{g} / \mathrm{mL}$, or zeocin $100 \mu \mathrm{g} / \mathrm{mL}$.

\section{Construction of mutant strains}

Mutant constructs were generated by splicing-by-overlap extension PCR as described previously ${ }^{55}$. Natural transformation and cotransformation were used to introduce mutant constructs into chitin-induced competent $V$. cholerae as described previously 56,57 , and mutations were confirmed by PCR and/or sequencing. All ectopic expression constructs were derived from previously published strains ${ }^{58}$. The specific primers used to generate mutant constructs can be found in Supplemental Table 3.

\section{Transposon mutagenesis and selection}

Transposon mutant libraries were generated with the mini-Tn10 delivery plasmid pDL1098 as previously described ${ }^{59}$. To carry out the genetic selection, the transposon mutant library was grown to $\mathrm{OD}_{600}$ of $\sim 2.5$ at $30^{\circ} \mathrm{C}$ shaking. Cultures were transferred to a stoppered argon-flushed glass tube and incubated statically at room temperature for 3 hours. The tube was then rinsed 5 times with LB to remove unbound cells. Bound cells were removed from the walls of the glass tube by vortexing vigorously with fresh LB. Samples were taken before and after incubation in the argon tube for quantitative plating. Cells retrieved after binding were used to inoculate the next round of selection. Six rounds of selection were carried out, at which point the binding frequency (CFU after incubation divided by CFU before incubation) matched the level of an $\mathrm{MshE}^{*}$ control. Then, a sample from the endpoint population was isolation streak plated and ten individual colonies were picked. The transposon-genomic junction in these colonies was amplified via inverse PCR and sent for Sanger sequencing to identify the gene mutated.

\section{Microscopy and image analysis}

All phase contrast and fluorescence images were obtained with a Nikon Ti-2 microscope with a Plan Apo $\times 60$ objective, a green fluorescent protein filter cube, a yellow fluorescent protein filter cube, a cyan fluorescent protein filter cube, an mCherry filter cube, a Hamamatsu ORCAFlash 4.0 camera, and Nikon NIS Elements imaging software. In strains expressing both GFP and CyPet, the GFP signal was imaged with the yellow fluorescent protein filter cube to minimize spectral overlap. Images were prepared with Fiji60,61. For experiments where bound cells needed to be quantified, the distinct fluorescence of each cell in the mixture was used to quantify the adherence of each cell type within each frame of the time lapse. Microbe $\mathrm{J}^{62}$ was used to automate this analysis on regions that contained $\sim 300$ total cells.

\section{MixD analysis}

Cells were first grown in LB $+100 \mu \mathrm{M}$ IPTG $++0.15 \%$ arabinose, where applicable) to $\mathrm{OD}_{600}$ of $\sim 2.5$ at $30^{\circ} \mathrm{C}$ rolling. Cultures were mixed at a 1:1 ratio, loaded onto a multiwell glass slide, and then covered with a glass coverslip. Each culture in these assays expressed a distinct fluorescent protein to help track each individual cell type by microscopy. For each sample, we captured a time-lapse series where phase contrast and fluorescence images were captured once every minute. Replicates were normalized by aligning the first time point to the frame immediately prior to the first recorded decrease in bound cells in the parent strain (i.e., when detachment occurs in the parent strain). Attached cell counts in subsequent frames were divided by the number of cells bound in the first frame.

\section{Assessing cell attachment}

To assess initial adherence of bacteria, cells were grown in LB (+ $100 \mu \mathrm{M} \mathrm{IPTG}$ and/or $0.15 \%$ arabinose, where applicable) to $\mathrm{OD}_{600}$ of $\sim 2.5$ at $30^{\circ} \mathrm{C}$ rolling. To assess the adherence of a single strain, a pure culture was loaded onto a multiwell glass slide and imaged by phase contrast microscopy. For experiments comparing initial attachment of $\mathrm{P}_{\mathrm{BAD}}-\mathrm{cdgJ}$ with parent, cells were mixed and added to a coverslip. Cells were allowed to bind aerobically prior to rinsing with instant ocean medium (7 $\mathrm{g} / \mathrm{L}$; Aquarium Systems). Rinsed spots were covered with a $0.2 \%$ gelzan pad and imaged. Binding frequency was determined by dividing cell counts for each mutant by the cell count of the parent strain.

To test the effect of access to air on cell adherence, $\sim 2 \mathrm{~mm}$ holes were sandblasted in the center of wells of a multiwell glass slide. Cells were grown overnight in LB $+100 \mu \mathrm{M} \mathrm{IPTG}$ at $30^{\circ} \mathrm{C}$ rolling. Cells were loaded onto a multiwell glass slide (either with or without a hole), covered with a glass coverslip, and imaged.

For large-scale binding assays, cells were grown to $\mathrm{OD}_{600}$ of $\sim 2.5$ at $30^{\circ} \mathrm{C}$ shaking and loaded into either an open glass tube (aerobic) or into a stoppered argon-flushed glass tube (microaerobic). Aerobic tubes were incubated on a roller drum, while microaerobic tubes were incubated statically. All cultures were incubated at room temperature for 3 hours and cells were allowed to bind to the tubes. After incubation, tubes were dumped and rinsed 5 times with fresh LB to remove unbound cells. Bound cells were then removed from the walls of the glass culture tube by vortexing for 1 min with $3 \mathrm{~mL}$ fresh LB. The cell slurry was then centrifuged and concentrated prior to quantitative plating. The binding frequency was calculated for each sample by dividing the CFU after incubation (bound cells) by the CFU before incubation (total cells). Five biological replicates were carried out for each strain.

For assessment of binding during PTIO scavenging, cells were first grown in LB $+100 \mu \mathrm{M}$ IPTG to an $\mathrm{OD}_{600}$ of $\sim 2.5$ at $30^{\circ} \mathrm{C}$ shaking. PTIO or Tiron (or an equivalent volume of DMSO vector control) were added to aliquots of these cultures to a final concentration of $4 \mathrm{mM}$. Cells were loaded onto a multiwell slide, covered with a coverslip, and incubated for 5 minutes prior to imaging.

For assessment of binding during incubation with DEA-NONOate, cells were first grown in LB $+100 \mu \mathrm{M}$ IPTG to an $\mathrm{OD}_{600}$ of $\sim 2.5$ at $30^{\circ} \mathrm{C}$ shaking. Cells were then mixed with DEA-NONOate (or an equivalent volume of $0.1 \mathrm{~N} \mathrm{NaOH}$ vector control) to a final 
concentration of $200 \mu \mathrm{M}$. Culture was added to a coverslip, and cells were allowed to bind aerobically prior to rinsing with instant ocean medium. Rinsed spots were covered with a $0.2 \%$ gelzan pad and imaged. Binding frequency was determined by dividing cell counts of the parent strain by the cell count of the mutant strain.

\section{Visualization of labelled pili}

To visualize pili in the context of a MixD assay, cells were first

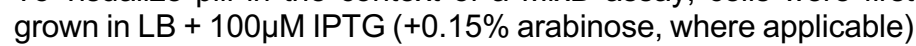
to $\mathrm{OD}_{600}$ of $\sim 2.5$ at $30^{\circ} \mathrm{C}$ rolling. Then, $\sim 10^{9}$ cells were spun down at $18,000 \times \mathrm{g}$ for $1 \mathrm{~min}$ and resuspended in instant ocean medium. Cells were then incubated with $25 \mu \mathrm{g} / \mathrm{mL}$ AF488-mal for $10 \mathrm{~min}$ at room temperature. Cells were washed twice to remove excess dye and resuspended in instant ocean medium. After labelling, the strain of interest and the parent strain were mixed at a ratio of 1:4, loaded onto a multiwell glass slide, covered with a glass coverslip, and imaged. For each sample, we captured a time-lapse series where phase contrast and fluorescence images were captured every 5 seconds.

To visualize pili in cultures incubated with DEA-NONOate (Fig. 5C), cells were labelled with AF488-mal as above, except cells were resuspended in spent LB medium. A 1:1 mixture of labelled cells was incubated with DEA-NONOate (or an equivalent volume of $0.1 \mathrm{~N} \mathrm{NaOH}$ vector control) to a final concentration of $200 \mu \mathrm{M}$. Samples were allowed to incubate at room temperature for 5 minutes and were then fixed by addition of paraformaldehyde to a final concentration of $2.5 \%$ and incubation at room temperature for 15 mins. Cells were then spun down at $18,000 \times \mathrm{g}$ for $1 \mathrm{~min}$ and resuspended in instant ocean medium. Samples were loaded onto a coverslip, covered with a $0.2 \%$ gelzan pad, and imaged. Twenty-five cells of each strain were randomly chosen and scored for the presence or absence of pili for each condition within each replicate.

\section{Oxygen quantification}

Oxygen levels in glass tubes, with and without culture, were measured with the non-invasive fiber optic PreSens Fibox 4 oxygen meter. Three biological replicates were measured for each scenario. A time course of culture-dependent oxygen-depletion was obtained by taking a measurement once per second after tubes were removed from the roller drum.

To indirectly detect the presence of oxygen with GFP maturation as a bioreporter, cells were first grown in LB $+100 \mu \mathrm{M}$ IPTG to $\mathrm{OD}_{600}$ of $\sim 2.5$ at $30^{\circ} \mathrm{C}$ rolling. Parent (expressing mCherry) and $P_{B A D}-G F P$ strains (expressing CyPet) were mixed in a 1:1 ratio and then supplemented with $0.2 \%$ arabinose. Immediately thereafter, $2.5 \mu \mathrm{L}$ of the mixture was added to a multiwell slide, covered with a coverslip, and imaged. Time-lapse series were recorded, capturing phase contrast and fluorescence images once every 5 minutes.

\section{c-di-GMP quantification}

Cells were grown aerobically and microaerobically exactly as described above for large-scale binding assays. Then, cultures were put on ice for 20 minutes. Equivalent volumes of cultures $\left(6.4 \mathrm{~mL}\right.$ of culture at $\left.\mathrm{OD}_{600} \sim 2.5\right)$ were spun down for $15 \mathrm{~min}$ at $8,000 \times \mathrm{g}$, at $4^{\circ} \mathrm{C}$. Cell pellets were frozen at $-80^{\circ} \mathrm{C}$ until all samples were prepared for c-di-GMP quantification.

Extraction of intracellular c-di-GMP was performed as previously described $^{63}$. Cell pellets were re-suspended in $1 \mathrm{~mL}$ of c-di-GMP extraction buffer (40\% acetonitrile, $40 \%$ methanol, $0.1 \%$ formic acid, $19.9 \%$ water), vortexed for $\sim 30$ seconds, and then incubated on ice for $15 \mathrm{~min}$. Extracted samples were then centrifuged at $16,000 \times g$ for $5 \mathrm{~min}$ at $4^{\circ} \mathrm{C}$, and $800 \mu \mathrm{l}$ of the c-di-GMP-containing supernatant was removed to a new $1.5 \mathrm{~mL}$ tube and dried under vacuum. Finally, the dried samples were re-suspended in $50 \mu \mathrm{l}$ of $184 \mathrm{mM} \mathrm{NaCl}$ and analyzed by liquid chromatography-tandem mass spectrometry (LC-MS/MS).

LC-MS/MS analysis was performed in conjunction with the UCSC Chemistry and Biochemistry Mass Spectrometry facility, using a Thermo LTQ-Orbitrap Velos Pro mass spectrometer coupled to a UPLC (Thermo). For UPLC separation, a Synergin Hydro $4 \mathrm{u}$ Fusion-RP $80 \mathrm{~A}$ column (150 mm x $2.00 \mathrm{~mm}$ diameter; 4- $\mu \mathrm{m}$ particle size) (Phenomenex, Torrance, CA) was used. Solvent A was $0.1 \%$ acetic acid in $10 \mathrm{mM}$ ammonium acetate, solvent $B$ was $0.1 \%$ formic acid in methanol. The gradient used was as follows: time $(t)=0-4 \mathrm{~min}, 98 \%$ solvent $A, 2 \%$ solvent $B ; t=10-15$ minutes, $5 \%$ solvent $A, 95 \%$ solvent $B$.

The c-di-GMP levels were calculated from a standard curve generated from pure c-di-GMP suspended in $184 \mathrm{mM} \mathrm{NaCl}$ (Sigma) at 0, 25, 50, 100, 500, $2000 \mathrm{nM}$. The assay is linear from 0 to $2000 \mathrm{nM}$ with an $\mathrm{R}^{2}$ of 0.999 . Finally, c-di-GMP levels were normalized to total protein per $\mathrm{mL}$ of culture. Cell pellets from 1 $\mathrm{mL}$ of each sample were lysed with $2 \%$ sodium dodecyl sulfate (SDS), and total protein levels of each sample were determined by BCA assay (Thermo). LC-MS/MS analysis was carried out on four biological replicates of each strain to quantify the abundance of c-di-GMP in each sample.

\section{Western blots}

Cells were grown aerobically and microaerobically exactly as described above for large-scale binding assays. Cells were spun down $\left(\sim 1.5 \times 10^{9} \mathrm{CFUs}\right)$ and resuspended in a lysis mix containing 1x FastBreak lysis buffer, $3.8 \mathrm{mg} / \mathrm{mL}$ lysozyme, and $\sim 25$ units benzonase in instant ocean medium. Cells were allowed to lyse for 10 minutes at room temperature, and then mixed $1: 1$ with $2 x$ SDS sample buffer [200 mM Tris pH 6.8, 25\% glycerol, 1.8\% SDS, $0.02 \%$ Bromophenol Blue, $5 \% \beta$-mercaptoethanol]. Cell lysates were separated by SDS PAGE $(10 \%$ gel $)$ and then electrophoretically transferred to a PVDF membrane. This membrane was then blotted with primary mouse monoclonal $\alpha$ FLAG M2 (Sigma) as described previously64 or with primary mouse monoclonal $\alpha-R p o A$ (Biolegend). Blots were washed and incubated with a-mouse secondary antibodies conjugated to horseradish peroxidase enzyme. Blots were developed with Pierce $^{\mathrm{TM}}$ ECL Western Blotting Substrate and then imaged with a ProteinSimple FluorChem E system.

\section{Phylogenetic analysis}

Phylogenetic tree of CdpA homologs among Vibrionaceae (Fig. S6) was constructed by first searching 287 publicly available, complete Vibrio genomes. A search with BUSCO v.4.0.565 returned 214 HMMs that were complete, non-duplicated, and common to each assembly. The homologous gene sequences for these common HMMs from each assembly were identified and their corresponding CDS sequences were multiple aligned in the context of their corresponding amino acid sequences with MUSCLE v.3.8.3166. The multiple sequence alignments for individual genes were concatenated from which a best scoring maximum likelihood tree was generated with RAxML v.8.2.1267. We used "Interactive Tree Of Life" webserver v.6 (https://itol.embl.de) for visualizing the resulting tree. We identified homologs to $V$. cholerae CdpA among these 287 genomes and overlaid the corresponding percent identity values on the tree.

Phylogenetic tree based on cdpA homology observed among eubacterial genomes (Fig. S7) was generated by first searching the CdpA HMM profile built from the $V$. cholerae CdpA homologs among the Vibrionales against the eubacterial protein sequences (subset of NCBI nr database, taxonomy id = 2), using HMMER v.3.3.2 (http://hmmer.org/). Sequences for hits with a minimum alignment length of 700 amino acids were obtained and a multiple 
sequence alignment was performed on them using MUSCLE v.3.8.3166 (parameters: -diags -sv -distance1 kbit20_3). A best scoring maximum likelihood tree was generated using RAxML ver.8.2.12 ${ }^{67}$. The nodes corresponding to the genus Vibrio were collapsed into a single node in blue, while those corresponding to the genus Aliivibrio were displayed in red.

The phylogenetic analysis showing presence or absence of CdpA homologs (Fig. 4E) was generated with a broadly representative set of genomes adapted from $\mathrm{Wu}$ and Eisen ${ }^{68}$. Phylosift ${ }^{69}$ identified and aligned 37 conserved protein sequences, which were subsequently concatenated into a combined alignment. RAxML ${ }^{67}$ estimated the maximum likelihood phylogeny using the LG amino acid substitution model with fixed residue frequencies and Gamma-distributed rate variation among sites.

Representative alignment of $\mathrm{CdpA}$ homologs of selected species was accomplished with T-Coffee, v.11.0 70,71 , and reformatted with BOXSHADE v.3.2.

\section{Detecting NO in liquid culture}

NO production in liquid culture was determined with DAR 4M-AM, a fluorescent $\mathrm{NO}$ indicator dye. For measurements under conditions that induce NO production in $E$. coli, cells were first grown to an $\mathrm{OD}_{600}$ of $\sim 2.5$ at $30^{\circ} \mathrm{C}$ shaking in $\mathrm{LB}+20 \mathrm{mM}$ sodium nitrate. Cultures were then incubated statically at room temperature for $3 \mathrm{hr}$. Cultures were centrifuged and resuspended in either fresh LB ("-N") or LB + $20 \mathrm{mM}$ nitrate ("+N") to a normalized $\mathrm{OD}_{600}$ of 2.5 . DAR-4M AM was then added to each reaction to a final concentration of $12.5 \mu \mathrm{M}$.

For measurements under conditions that induce detachment in $\mathrm{V}$. cholerae ("-air"), cells were first grown to an $\mathrm{OD}_{600}$ of $\sim 2.5$ at $30^{\circ} \mathrm{C}$ shaking in LB. $1 \mathrm{~mL}$ culture was loaded into a stoppered argonflushed glass tube (microaerobic), DAR-4M AM was added to a final concentration of $12.5 \mu \mathrm{M}$, and the culture was then allowed to incubate at room temperature for $3 \mathrm{hr}$.

For measurements of NO production by a chemical NO donor, DEA-NONOate was added to final concentrations of $100 \mu \mathrm{M}, 40$ $\mu \mathrm{M}$, or $10 \mu \mathrm{M}$ in either fresh LB or cultures of $E$. coli grown in LB to an $\mathrm{OD}_{600}$ of $\sim 2.5$ at $30^{\circ} \mathrm{C}$ shaking (i.e., conditions where endogenous NO is not produced). DAR-4M AM was then added to each reaction to a final concentration of $12.5 \mu \mathrm{M}$.

Fluorescence of all samples was kinetically monitored with a BioTek Synergy H1M microplate reader with excitation set to 500 $\mathrm{nm}$ and emission set to $590 \mathrm{~nm}$.

\section{CdpA purification and in vitro PDE activity assays}

CdpA was cloned into a pET20b vector appending a $6 \mathrm{xHis}$ tag at the $\mathrm{C}$ terminus by the use of Ndel and Xhol restrictions enzymes. The resulting plasmid was transformed into BL21 (DE3) pLysS cells. Transformed cells were grown in yeast extract media $(4.5 \%$ Yeast extract with $17 \mathrm{mM} \mathrm{NaH}_{2} \mathrm{PO}_{4}$ and $72 \mathrm{mM} \mathrm{Na}_{2} \mathrm{HPO}_{4}, \mathrm{pH} 7.5$ ). Expression was induced at $\mathrm{OD}_{595}$ of 0.8 with $25 \mu \mathrm{M}$ IPTG and carried out overnight at $16^{\circ} \mathrm{C} .0 .1 \mathrm{mM}$ ALA (ס-aminolevulinic acid) was added at the time of induction. For purification, cells were lysed by sonication in buffer containing $20 \mathrm{mM}$ Tris- $\mathrm{HCl}, 250 \mathrm{mM}$ $\mathrm{KCl}, 10 \%$ glycerol, $5 \mathrm{mM}$ 2-mercaptoethanol, $50 \mu \mathrm{M}$ EDTA, $1 \mathrm{mM}$ PMSF, $1 \%$ Triton $\mathrm{X}-100$, and $20 \mu \mathrm{M}$ hemin, $\mathrm{pH}$ 8.0. Cleared lysate was loaded on a nickel-NTA (GE) column and the protein was eluted using an imidazole gradient. Three wash steps were performed: $100 \mathrm{ml}$ of $10 \mathrm{mM}$ imidazole, $50 \mathrm{ml}$ of $20 \mathrm{mM}$ imidazole and $5 \mathrm{ml}$ of $50 \mathrm{mM}$ imidazole. After washing, the proteins were eluted in buffer with $250 \mathrm{mM}$ imidazole and desalted with a PD-10 column (GE) in buffer containing $50 \mathrm{mM}$ Tris, $250 \mathrm{mM} \mathrm{KCl,} 5 \mathrm{mM}$ 2-mercaptoethanol, $\mathrm{pH} 8.0$.
PDE assays were performed at $25^{\circ} \mathrm{C}$ overnight in an assay buffer containing $50 \mathrm{mM}$ Tris- $\mathrm{HCl}, 5 \mathrm{mM} \mathrm{MgCl}_{2}, 50 \mu \mathrm{M} \mathrm{c}$-di-GMP and $\mathrm{pH}$ 8.0. Reactions were initiated by the addition of $50 \mathrm{nM}$ of purified protein. Reactions were quenched by addition of $10 \mathrm{mM} \mathrm{CaCl}_{2}$ and subsequent heating to $95^{\circ} \mathrm{C}$ for $5 \mathrm{~min}$ to precipitate protein. Precipitated protein was removed by centrifugation and the resulting supernatant was filtered through a $0.22 \mu \mathrm{m}$ membrane and analyzed by HPLC on a reverse phase C18 column (Shimazu) with an ion pairing buffer system.

\section{$\triangle$ Nap growth assay}

Cells were inoculated into M9 $+1 \%$ glucose $+/-20 \mathrm{mM}$ sodium nitrate in a stoppered argon-flushed glass tube (microaerobic) and allowed to grow for $24 \mathrm{hr}$ at $30^{\circ} \mathrm{C}$ static. Growth was assessed by measuring the final $\mathrm{OD}_{600}$ of cultures.

\section{Statistics}

Statistical differences were determined using one-way ANOVA tests and post-hoc Holm-Šídák test, $\alpha=0.5$, or by two-tailed Student's t-test, as noted in the figure legends. Statistical comparisons for MixD, binding frequency, western blot, piliation, and initial binding experiments were performed on the logtransformed data. All statistical comparisons were performed with GraphPad Prism software version 9.0.1. All means and statistical comparisons can be found in Supplemental Tables 4 and 5 , respectively.

\section{Data availability}

The data that support the findings of this study are available from the corresponding author upon request.

\section{REFERENCES}

1 Denise, R., Abby, S. S. \& Rocha, E. P. C. Diversification of the type IV filament superfamily into machines for adhesion, protein secretion, DNA uptake, and motility. PLOS Biology 17, e3000390-e3000390, doi:10.1371/journal.pbio.3000390 (2019).

2 Ellison, C. K. et al. Retraction of DNA-bound type IV competence pili initiates DNA uptake during natural transformation in Vibrio cholerae. Nature Microbiology 3, 773780, doi:10.1038/s41564-018-0174-y (2018).

3 Merz, A. J., So, M. \& Sheetz, M. P. Pilus retraction powers bacterial twitching motility. Nature 407, 98-102, doi:10.1038/35024105 (2000).

4 O'Toole, G. A. \& Kolter, R. Flagellar and twitching motility are necessary for Pseudomonas aeruginosa biofilm development. Molecular Microbiology 30, 295-304 (1998).

5 Ellison, C. K. et al. Obstruction of pilus retraction stimulates bacterial surface sensing. Science 358, 535-538, doi:10.1126/science.aan5706 (2017).

6 Berne, C., Ellison, C. K., Ducret, A. \& Brun, Y. V. Bacterial adhesion at the single-cell level. Nature Reviews Microbiology 16, 616-627, doi:10.1038/s41579-018-0057-5 (2018).

7 Craig, L., Pique, M. E. \& Tainer, J. A. Type IV pilus structure and bacterial pathogenicity. Nature Reviews Microbiology 2, 363-378, doi:10.1038/nrmicro885 (2004).

8 Craig, L., Forest, K. T. \& Maier, B. Type IV pili: dynamics, biophysics and functional consequences. Nature Reviews Microbiology, doi:10.1038/s41579-019-0195-4 (2019).

9 McCallum, M., Tammam, S., Khan, A., Burrows, L. L. \& Howell, P. L. The molecular mechanism of the type IVa pilus motors. Nature Communications 8, 15091-15091, doi:10.1038/ncomms15091 (2017).

10 Chang, Y. W. et al. Architecture of the type IVa pilus machine. Science 351, aad2001, doi:10.1126/science.aad2001 (2016).

11 Watnick, P. I., Fullner, K. J. \& Kolter, R. A role for the mannosesensitive hemagglutinin in biofilm formation by Vibrio cholerae El Tor. Journal of bacteriology 181, 3606-3609 (1999). 
12 Watnick, P. I. \& Kolter, R. Steps in the development of a Vibrio cholerae El Tor biofilm. Molecular microbiology 34, 586-595 (1999).

13 Meibom, K. L. et al. The Vibrio cholerae chitin utilization program. 2524-2529 (2004).

14 Floyd, K. A. et al. c-di-GMP modulates type IV MSHA pilus retraction and surface attachment in Vibrio cholerae. Nat Commun 11, 1549, doi:10.1038/s41467-020-15331-8 (2020).

15 Whitchurch, C. B., Hobbs, M., Livingston, S. P., Krishnapillai, V. \& Mattick, J. S. Characterisation of a Pseudomonas aeruginosa twitching motility gene and evidence for a specialised protein export system widespread in eubacteria. Gene 101, 33-44 (1990).

16 Chlebek, J. L. et al. PilT and PilU are homohexameric ATPases that coordinate to retract type IVa pili. PLOS Genetics 15, e1008448-e1008448, doi:10.1371/journal.pgen.1008448 (2019).

17 Adams, D. W., Pereira, J. M., Stoudmann, C., Stutzmann, S. \& Blokesch, M. The type IV pilus protein PilU functions as a PilT-dependent retraction ATPase. PLoS Genet 15, e1008393, doi:10.1371/journal.pgen.1008393 (2019).

18 Jenal, U. \& Malone, J. Mechanisms of Cyclic-di-GMP Signaling in Bacteria. doi:10.1146/annurev.genet.40.110405.090423 (2006).

19 Jones, C. J. et al. C-di-GMP Regulates Motile to Sessile Transition by Modulating MshA Pili Biogenesis and NearSurface Motility Behavior in Vibrio cholerae. PLOS Pathogens 11, e1005068-e1005068, doi:10.1371/journal.ppat.1005068 (2015).

20 Wang, Y.-C. et al. Nucleotide binding by the widespread highaffinity cyclic di-GMP receptor MshEN domain. Nature Communications 7, 12481-12481, doi:10.1038/ncomms12481 (2016).

21 Nakhamchik, A., Wilde, C. \& Rowe-Magnus, D. A. Cyclic-diGMP regulates extracellular polysaccharide production, biofilm formation, and rugose colony development by Vibrio vulnificus. Appl Environ Microbiol 74, 4199-4209, doi:10.1128/AEM.00176-08 (2008).

22 Fong, J. C. \& Yildiz, F. H. The rbmBCDEF gene cluster modulates development of rugose colony morphology and biofilm formation in Vibrio cholerae. J Bacteriol 189, 23192330, doi:10.1128/JB.01569-06 (2007).

23 Tsien, R. Y. The green fluorescent protein. Annu Rev Biochem 67, 509-544, doi:10.1146/annurev.biochem.67.1.509 (1998).

24 Tamayo, R., Schild, S., Pratt, J. T. \& Camilli, A. Role of cyclic Di-GMP during El Tor biotype Vibrio cholerae infection: Characterization of the in vivo-induced cyclic Di-GMP phosphodiesterase CdpA. Infection and immunity 76, 16171627, doi:10.1128/IAI.01337-07 (2008).

25 Heckler, I., Hossain, S. \& Boon, E. M. Heme inhibits the activity of a c-di-GMP phosphodiesterase in Vibrio cholerae. Biochemical and Biophysical Research Communications 529, 1112-1116, doi:10.1016/j.bbrc.2020.06.048 (2020).

26 Tuckerman, J. R. et al. An oxygen-sensing diguanylate cyclase and phosphodiesterase couple for c-di-GMP control. Biochemistry 48, 9764-9774, doi:10.1021/bi901409g (2009).

27 Chang, A. L. et al. Phosphodiesterase A1, a Regulator of Cellulose Synthesis in Acetobacter xylinum, Is a Heme-Based Sensor. Biochemistry 40, 3420-3426 (2001).

28 Sawai, $H$. et al. Molecular oxygen regulates the enzymatic activity of a heme-containing diguanylate cyclase (HemDGC) for the synthesis of cyclic di-GMP. Biochim Biophys Acta 1804, 166-172, doi:10.1016/j.bbapap.2009.09.028 (2010).

29 Kitanishi, K. et al. Important roles of Tyr43 at the putative heme distal side in the oxygen recognition and stability of the $\mathrm{Fe}(\mathrm{II})$ $\mathrm{O} 2$ complex of YddV, a globin-coupled heme-based oxygen sensor diguanylate cyclase. Biochemistry 49, 10381-10393, doi:10.1021/bi100733q (2010).
30 Hossain, S. \& Boon, E. M. Discovery of a Novel Nitric Oxide Binding Protein and Nitric-Oxide-Responsive Signaling Pathway in Pseudomonas aeruginosa. ACS Infect Dis 3, 454461, doi:10.1021/acsinfecdis.7b00027 (2017).

31 Zumft, W. G. Cell biology and molecular basis of denitrification. Microbiol Mol Biol Rev 61, 533-616 (1997).

32 Rinaldo, S., Giardina, G., Mantoni, F., Paone, A. \& Cutruzzola, F. Beyond nitrogen metabolism: nitric oxide, cyclic-di-GMP and bacterial biofilms. FEMS Microbiol Lett 365, doi:10.1093/femsle/fny029 (2018).

33 Goldstein, S., Russo, A. \& Samuni, A. Reactions of PTIO and carboxy-PTIO with *NO, *NO2, and O2-" 50949-50955, doi:10.1074/jbc.M308317200 (2003).

34 Bueno, E., Pinedo, V. \& Cava, F. Adaptation of Vibrio cholerae to Hypoxic Environments. Front Microbiol 11, 739, doi:10.3389/fmicb.2020.00739 (2020).

35 Bueno, E., Sit, B., Waldor, M. K. \& Cava, F. Genetic Dissection of the Fermentative and Respiratory Contributions Supporting Vibrio cholerae Hypoxic Growth. J Bacteriol 202, doi:10.1128/JB.00243-20 (2020).

36 Edward N. Janoff, H. H., David N. Taylor, Claudine E. Fasching, Julie R. Kenner, Edgar Jaimes, Leopoldo Raij. Nitric oxide production during Vibrio cholerae infection. American Journal of Physiology-Gastrointestinal and Liver Physiology 273 (1997).

37 Davies, B. W. et al. DNA damage and reactive nitrogen species are barriers to Vibrio cholerae colonization of the infant mouse intestine. PLoS Pathog 7, e1001295, doi:10.1371/journal.ppat.1001295 (2011).

38 Stern, A. M. et al. The NorR regulon is critical for Vibrio cholerae resistance to nitric oxide and sustained colonization of the intestines. mBio 3, e00013-00012, doi:10.1128/mBio.00013-12 (2012).

39 Bueno, E., Sit, B., Waldor, M. K. \& Cava, F. Anaerobic nitrate reduction divergently governs population expansion of the enteropathogen Vibrio cholerae. Nat Microbiol 3, 1346-1353, doi:10.1038/s41564-018-0253-0 (2018).

40 Vine, C. E., Purewal, S. K. \& Cole, J. A. NsrR-dependent method for detecting nitric oxide accumulation in the Escherichia coli cytoplasm and enzymes involved in NO production. FEMS Microbiol Lett 325, 108-114, doi:10.1111/j.1574-6968.2011.02385.x (2011).

41 Ellison, C. K. et al. Acinetobacter baylyi regulates type IV pilus synthesis by employing two extension motors and a motor protein inhibitor. bioRxiv, doi:10.1101/2020.09.28.317149 (2021).

42 Shah, M. et al. A phage-encoded anti-activator inhibits quorum sensing in Pseudomonas aeruginosa. Mol Cell 81, 571-583 e576, doi:10.1016/j.molcel.2020.12.011 (2021).

43 Mercier, R. et al. The polar Ras-like GTPase MglA activates type IV pilus via SgmX to enable twitching motility in Myxococcus xanthus. Proc Natl Acad Sci U S A 117, 2836628373, doi:10.1073/pnas.2002783117 (2020).

44 DeLange, P. A., Collins, T. L., Pierce, G. E. \& Robinson, J. B. PilJ localizes to cell poles and is required for type IV pilus extension in Pseudomonas aeruginosa. Curr Microbiol 55, 389-395, doi:10.1007/s00284-007-9008-5 (2007).

45 Bulyha, I. et al. Regulation of the type IV pili molecular machine by dynamic localization of two motor proteins. Mol Microbiol 74, 691-706, doi:10.1111/j.1365-2958.2009.06891.x (2009).

46 Kühn, M. J. et al. Mechanotaxis directs Pseudomonas aeruginosa twitching motility. bioRxiv, doi:10.1101/2021.01.26.428277 (2021).

47 Conner, J. G., Zamorano-Sanchez, D., Park, J. H., Sondermann, H. \& Yildiz, F. H. The ins and outs of cyclic diGMP signaling in Vibrio cholerae. Curr Opin Microbiol 36, 2029, doi:10.1016/j.mib.2017.01.002 (2017). 
bioRxiv preprint doi: https://doi.org/10.1101/2021.04.20.440694; this version posted April 20, 2021. The copyright holder for this preprint (which was not certified by peer review) is the author/funder. All rights reserved. No reuse allowed without permission.

48 Townsley, L. \& Yildiz, F. H. Temperature affects c-di-GMP signalling and biofilm formation in Vibrio cholerae. Environ Microbiol 17, 4290-4305, doi:10.1111/1462-2920.12799 (2015).

49 Koestler, B. J. \& Waters, C. M. Bile acids and bicarbonate inversely regulate intracellular cyclic di-GMP in Vibrio cholerae. Infect Immun 82, 3002-3014, doi:10.1128/IAI.0166414 (2014).

50 Schaller, R. A., Ali, S. K., Klose, K. E. \& Kurtz, D. M., Jr. A bacterial hemerythrin domain regulates the activity of a Vibrio cholerae diguanylate cyclase. Biochemistry 51, 8563-8570, doi:10.1021/bi3011797 (2012).

51 Hsiao, A., Liu, Z., Joelsson, A. \& Zhu, J. Vibrio cholerae virulence regulator-coordinated evasion of host immunity. Proc Natl Acad Sci $U S S$ A 103, 14542-14547, doi:10.1073/pnas.0604650103 (2006).

52 Hsiao, A., Toscano, K. \& Zhu, J. Post-transcriptional cross-talk between pro- and anti-colonization pili biosynthesis systems in Vibrio cholerae. Molecular Microbiology 67, 849-860, doi:10.1111/j.1365-2958.2007.06091.x (2007).

53 Chun, C., Zheng, L. \& Colgan, S. P. Tissue metabolism and host-microbial interactions in the intestinal mucosa. Free Radic Biol Med 105, 86-92, doi:10.1016/j.freeradbiomed.2016.09.027 (2017).

54 Zheng, L., Kelly, C. J. \& Colgan, S. P. Physiologic hypoxia and oxygen homeostasis in the healthy intestine. A Review in the Theme: Cellular Responses to Hypoxia. Am J Physiol Cell Physiol 309, C350-360, doi:10.1152/ajpcell.00191.2015 (2015).

55 Dalia, A. B., Lazinski, D. W. \& Camilli, A. Characterization of undermethylated sites in Vibrio cholerae. J Bacteriol 195, 2389-2399, doi:10.1128/JB.02112-12 (2013).

56 Dalia, A. B., McDonough, E. \& Camilli, A. Multiplex genome editing by natural transformation. Proc Natl Acad Sci U S A 111, 8937-8942, doi:10.1073/pnas.1406478111 (2014).

57 Dalia, T. N. et al. Multiplex Genome Editing by Natural Transformation (MuGENT) for Synthetic Biology in Vibrio natriegens. ACS Synth Biol 6, 1650-1655, doi:10.1021/acssynbio.7b00116 (2017).

58 Dalia, T. N., Chlebek, J. L. \& Dalia, A. B. A modular chromosomally integrated toolkit for ectopic gene expression in Vibrio cholerae. Sci Rep 10, 15398, doi:10.1038/s41598020-72387-8 (2020).

59 McDonough, E., Lazinski, D. W. \& Camilli, A. Identification of in vivo regulators of the Vibrio cholerae xds gene using a highthroughput genetic selection. Mol Microbiol 92, 302-315, doi:10.1111/mmi.12557 (2014).
60 Rueden, C. T. et al. ImageJ2: ImageJ for the next generation of scientific image data. BMC Bioinformatics 18, 529, doi:10.1186/s12859-017-1934-z (2017).

61 Schindelin, J. et al. Fiji: an open-source platform for biologicalimage analysis. Nature Methods 9, 676-682, doi:10.1038/nmeth.2019 (2012).

62 Ducret, A., Quardokus, E. M. \& Brun, Y. V. MicrobeJ, a tool for high throughput bacterial cell detection and quantitative analysis. Nat Microbiol 1, 16077, doi:10.1038/nmicrobiol.2016.77 (2016).

63 Liu, X., Beyhan, S., Lim, B., Linington, R. G. \& Yildiz, F. H. Identification and Characterization of a Phosphodiesterase That Inversely Regulates Motility and Biofilm Formation in Vibrio cholerae. Journal of Bacteriology 192, 4541-4552, doi:10.1128/jb.00209-10 (2010).

64 Shin, J. H., Lanz, M., Smolka, M. B. \& Dorr, T. Characterization of an anti-FLAG antibody binding protein in V. cholerae. Biochem Biophys Res Commun 528, 493-498, doi:10.1016/j.bbrc.2020.05.169 (2020).

65 Simao, F. A., Waterhouse, R. M., loannidis, P., Kriventseva, E. V. \& Zdobnov, E. M. BUSCO: assessing genome assembly and annotation completeness with single-copy orthologs. Bioinformatics 31 , 3210-3212, doi:10.1093/bioinformatics/btv351 (2015).

66 Edgar, R. C. MUSCLE: a multiple sequence alignment method with reduced time and space complexity. BMC Bioinformatics 5, 113, doi:10.1186/1471-2105-5-113 (2004).

67 Stamatakis, A. RAxML version 8: a tool for phylogenetic analysis and post-analysis of large phylogenies. Bioinformatics 30, 1312-1313, doi:10.1093/bioinformatics/btu033 (2014).

$68 \mathrm{Wu}, \mathrm{M}$. \& Eisen, J. A. A simple, fast, and accurate method of phylogenomic inference. Genome Biol 9, R151, doi:10.1186/gb-2008-9-10-r151 (2008).

69 Darling, A. E. et al. PhyloSift: phylogenetic analysis of genomes and metagenomes. PeerJ 2, e243, doi:10.7717/peerj.243 (2014).

70 Di Tommaso, P. et al. T-Coffee: a web server for the multiple sequence alignment of protein and RNA sequences using structural information and homology extension. Nucleic Acids Res 39, W13-17, doi:10.1093/nar/gkr245 (2011).

71 Notredame, C., Higgins, D. G. \& Heringa, J. T-Coffee: A novel method for fast and accurate multiple sequence alignment. $J$ Mol Biol 302, 205-217, doi:10.1006/jmbi.2000.4042 (2000).

72 Blattner, F. R. et al. The complete genome sequence of Escherichia coli K-12. Science 277, 1453-1462, doi:10.1126/science.277.5331.1453 (1997). 


\section{Supplemental Information for:}

\section{Oxygen depletion and nitric oxide stimulate type IV MSHA pilus retraction in Vibrio cholerae via activation of the phosphodiesterase CdpA}

Hannah Q. Hughes ${ }^{1}$, Kyle A. Floyd ${ }^{2}$, Sajjad Hossain ${ }^{3}$, Sweta Anantharaman ${ }^{3}$, David T. Kysela ${ }^{4}$, Yuanchen $\mathrm{Yu}^{5}$, Michael P. Kappler ${ }^{5}$, Triana N. Dalia ${ }^{1}$, Ram C. Podicheti ${ }^{6}$, Douglas B. Rusch ${ }^{6}$, Yves V. Brun ${ }^{4}$, Stephen C. Jacobson ${ }^{5}$, James B. McKinlay ${ }^{1}$, Fitnat H. Yildiz ${ }^{2}$, Elizabeth M. Boon $^{3}$, and Ankur B. Dalia ${ }^{1, *}$.

${ }^{1}$ Department of Biology, Indiana University, Bloomington, IN

${ }^{2}$ Department of Microbiology and Environmental Toxicology, University of California - Santa Cruz, Santa Cruz, CA

${ }^{3}$ Department of Chemistry and Institute of Chemical Biology \& Drug Discovery, Stony Brook University, Stony Brook, NY

${ }^{4}$ Department of Microbiology, Infectious Diseases, and Immunology, Université de Montréal, Montreal, Quebec, Canada

${ }^{5}$ Department of Chemistry, Indiana University, Bloomington, IN

${ }^{6}$ Center for Genomics and Bioinformatics, Indiana University, Bloomington, IN

*Author for correspondence: ankdalia@indiana.edu

This document includes:

Figs. S1-S9

Movies SM1-SM5 figure legends

Tables S1-S5 
A

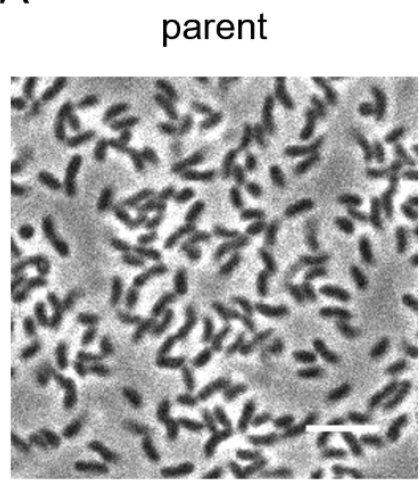

parent $\triangle \mathrm{MSHA}$

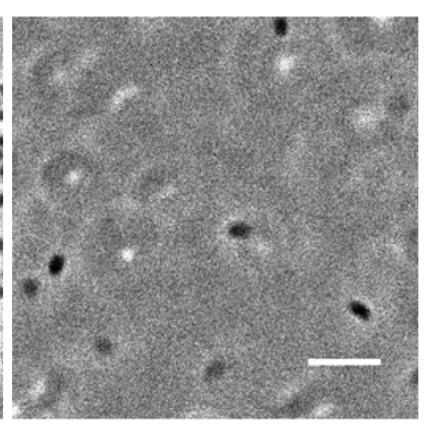

$\mathrm{B}$

$P_{B A D}-d c p A \Delta v p s$

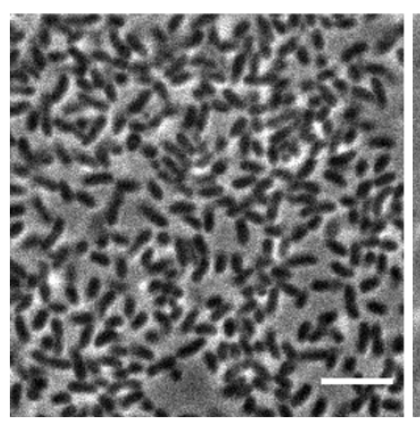

$P_{B A D^{-}}-d c p A \Delta v p s$ $\triangle \mathrm{MSHA}$
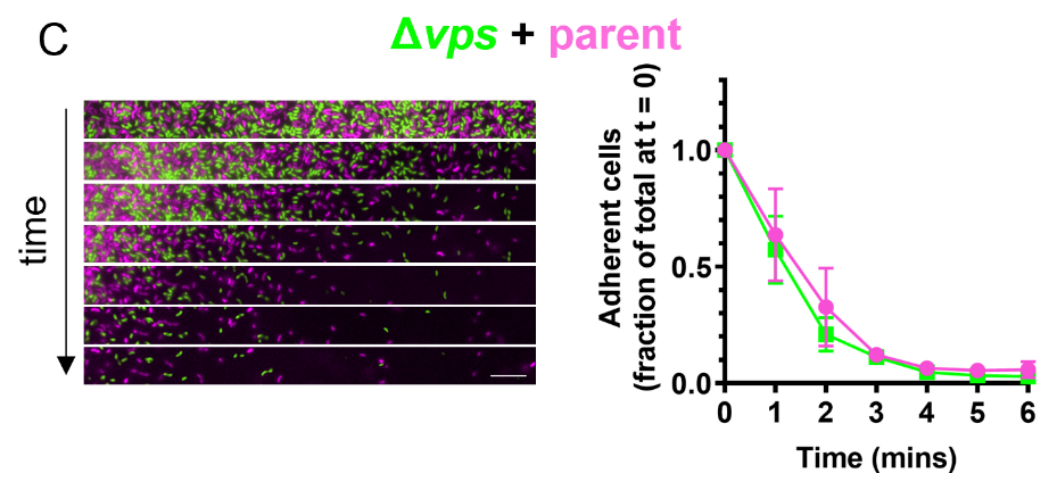

\section{Supplemental Figure 1: MSHA pili, but not vps, are required for initial cell attachment.}

(A-B) Representative phase contrast images showing surface binding in the indicated strain backgrounds. $\triangle M S H A$ signifies deletion of the entire MSHA pilus operon ( $\triangle$ VC0399 - VC0414).

Importantly, deleting the MSHA pilus operon from the $\mathrm{P}_{\mathrm{BAD}}-d c p A \triangle v p s$ strain prevented attachment, even under induction of $d c p A$ (cells in $\mathbf{B}$ were grown with $0.15 \%$ arabinose), indicating that attachment is dependent on MSHA pili in this background. Scale bar $=5 \mu \mathrm{m}$. (C) MixD assay of $\Delta v p s$ expressing GFP (green) and a parent strain expressing mCherry (fuchsia). Representative montage of time-lapse imaging (left) with 1-minute intervals between frames. Scale bar $=10 \mu \mathrm{m}$. Quantification of three biological replicates is shown in the line graph (right) and is displayed as the mean \pm SD. 


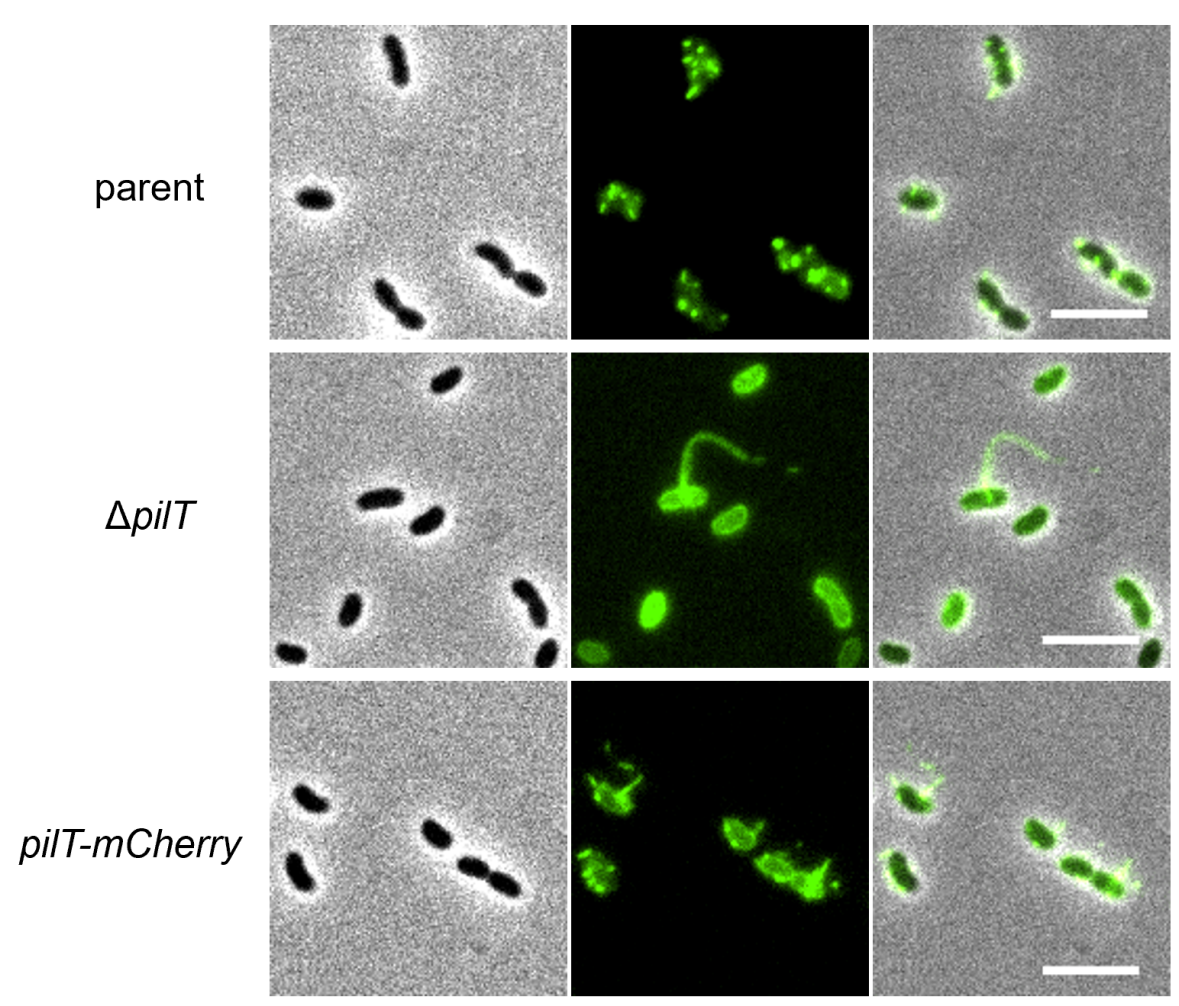

Supplemental Figure 2: PilT-mCherry cells retain MSHA surface piliation, unlike $\Delta$ pilT cells.

Representative images showing piliation states of parent, $\Delta$ pilT, and pilT-mCherry strains. Phase images (left) show cell boundaries, FITC images (middle) show AF488-mal labelled MSHA pili, and the overlay is shown on the right. Production of pili is rare in $\Delta$ pilT cells, but when observed, cells make a single long pilus as depicted in the representative image. Scale bar $=5 \mu \mathrm{m}$. 

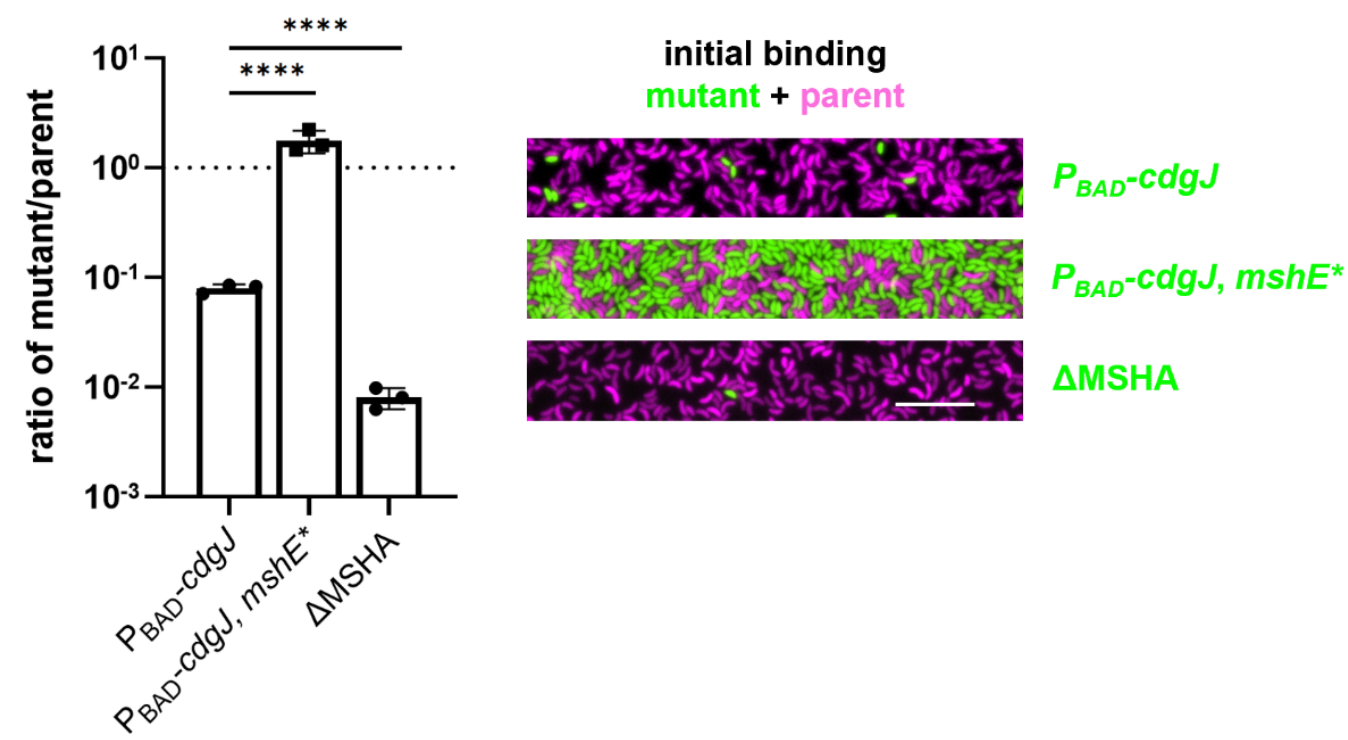

$\triangle M S H A$

\section{Supplemental Figure 3: Increasing PDE activity prevents cell attachment in a manner that is dependent on the allosteric regulation of MshE activity.}

Quantification (left) of initial attachment of a 1:1 mixture of the parent and the mutant strain indicated on the $\mathrm{X}$-axis. Ratio is determined by dividing the number of attached mCherry expressing parent cells (fuchsia) by the number of attached GFP-expressing mutant cells (green) as depicted in the representative images shown on the right. If strains bind equally well, the expected ratio is 1 , which is indicated by the dotted line. Data are from three independent experiments and shown as the mean \pm SD with at least 240 cells analyzed per replicate. Statistical comparisons were made with ANOVA and posthoc Holm-Šídák test. ${ }^{* * *} P<0.0001$. Scale bar $=10 \mu \mathrm{m}$. 
A

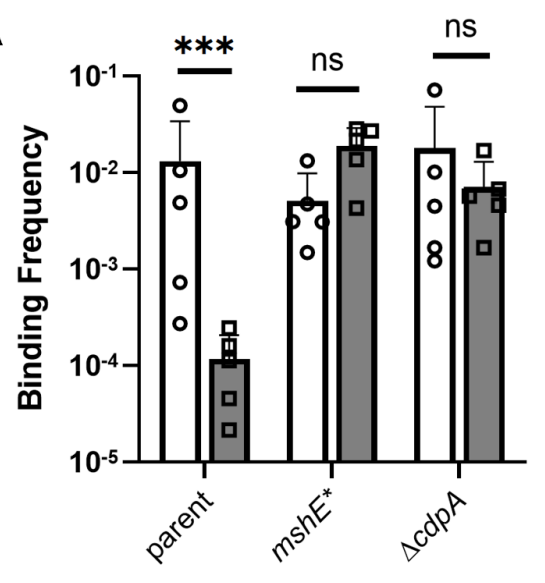

B

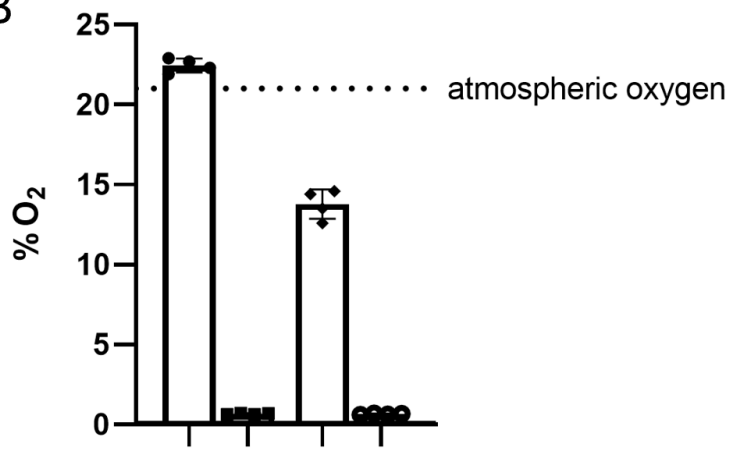

C

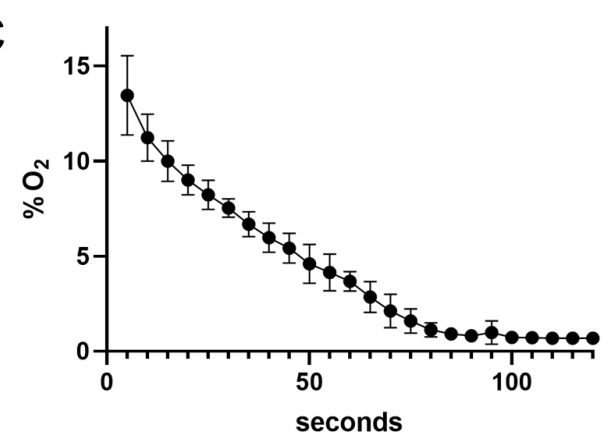

\section{Supplemental Figure 4: Large-scale binding assays in glass culture tubes match MixD phenotypes}

(A) Large-scale binding assays of cultures incubated in aerobic (open bars) or microaerobic conditions (shaded bars). Data are from five independent biological replicates and shown as the mean \pm SD.

Statistical comparisons were made by one-way ANOVA and post-hoc Holm-Šídák test. ${ }^{* * *} P<0.001$. (B) Oxygen levels in aerobic vs. microaerobic growth conditions. "+ air" indicates tubes that were incubated rolling, open to the air. "- air" indicates tubes that were flushed with argon and sealed. Initial $\% \mathrm{O}_{2}$ is displayed in the open bars, and $\% \mathrm{O}_{2}$ after incubation with culture is displayed in the shaded bars. (C) Oxygen levels of the aerobic culture upon transition from rolling to static incubation. Graphs B and C represent 4 independent biological replicates and are shown as the mean \pm SD. 

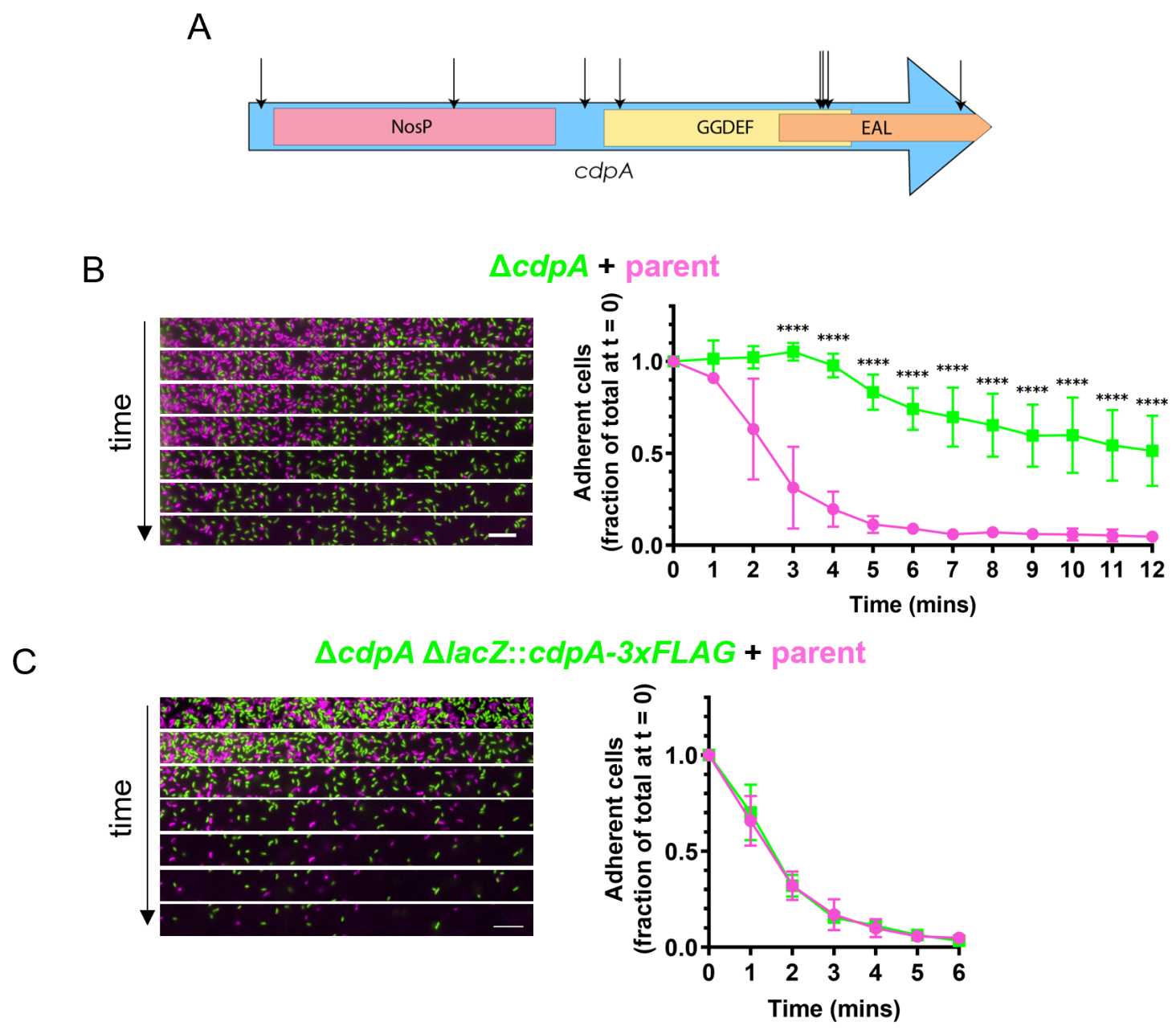

\section{Supplemental Figure 5: CdpA is required for optimal cell detachment from slides.}

(A) Schematic of the domain architecture of CdpA. Black arrows indicate transposon insertion sites recovered during our genetic selection. (B-C) MixD assays of $\triangle c d p A$ and $c d p A-3 x F L A G$ strains expressing GFP (green) with a parent strain expressing mCherry (fuschia). Representative montages of time-lapse imaging (left) with 1-minute intervals between frames. Scale bar $=10 \mu \mathrm{m}$. Quantification of three biological replicates is shown in each line graph (right) and is displayed as the mean \pm SD. Statistical comparisons were made by one-way ANOVA and post-hoc Holm-Šídák test. ${ }^{* * *} P<0.0001$. 
Tree scale: 0.1 H

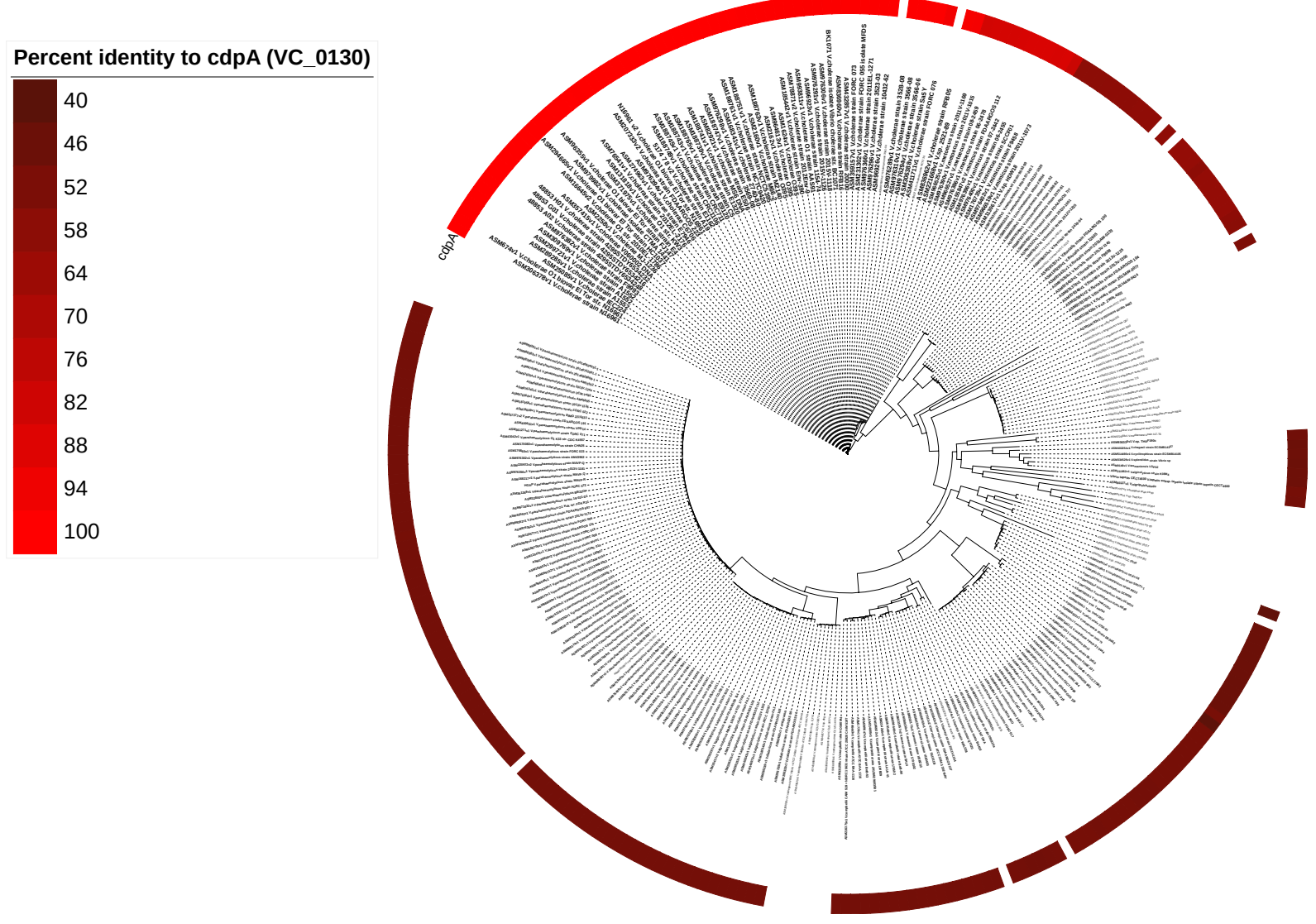

\section{Supplemental Figure 6: CdpA is widely conserved among the Vibrionaceae.}

Phylogenetic tree of Vibrio genus derived from a multi-locus protein multiple sequence alignment. Strains that encode homologs of $c d p A$ are denoted with a red bar, and the brightness of the bar corresponds to the percent identity with $V$. cholerae CdpA (VC0130). 
bioRxiv preprint doi: https://doi.org/10.1101/2021.04.20.440694; this version posted April 20, 2021. The copyright holder for this preprint (which was not certified by peer review) is the author/funder. All rights reserved. No reuse allowed without permission.

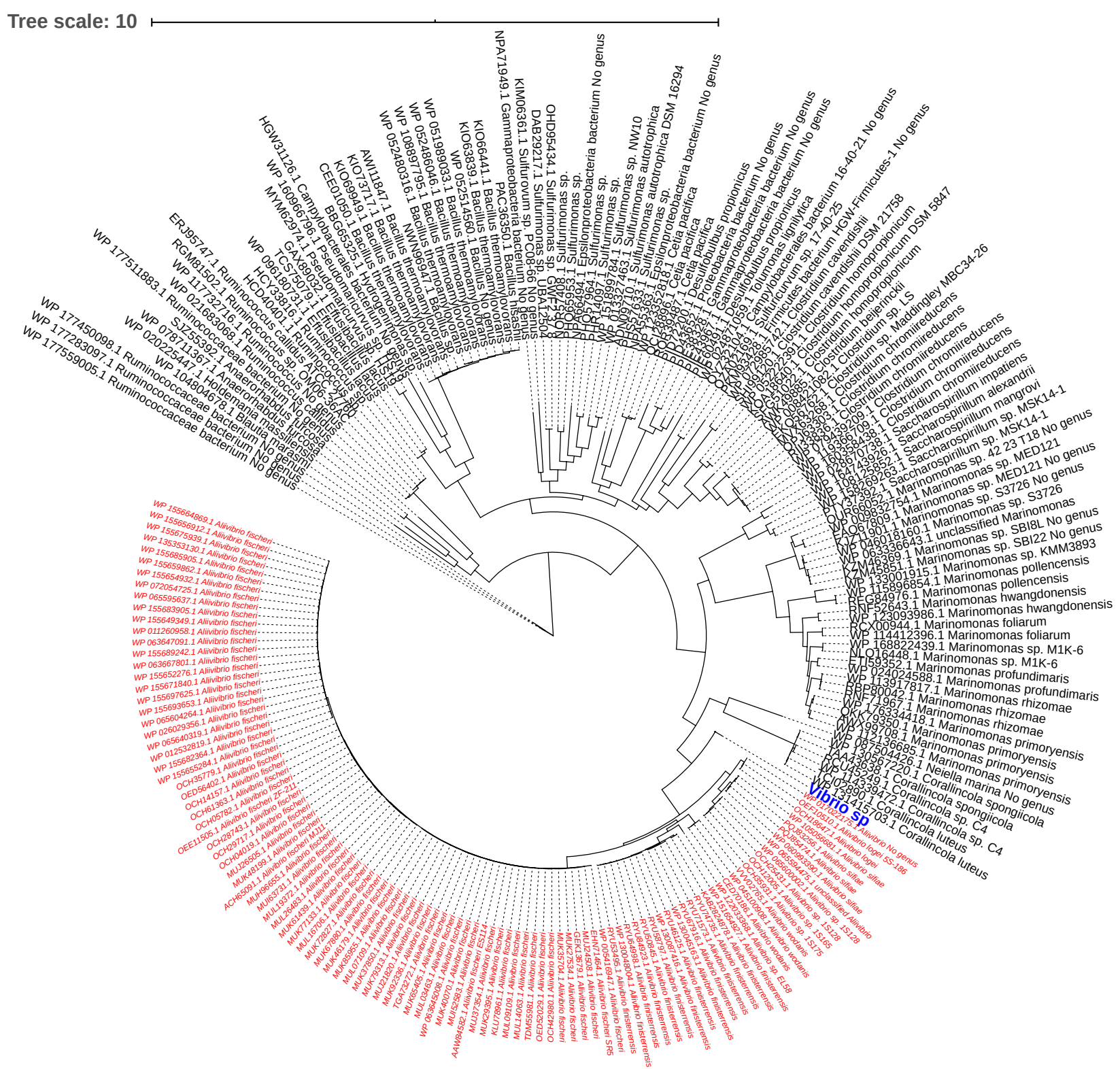

\section{Supplemental Figure 7: CdpA homologs are found in diverse eubacteria.}

Phylogenetic tree of CdpA containing eubacteria derived from a CpdA protein multiple sequence alignment. Vibrio species (blue) are condensed into a single node and Allivibrio species are designated by red text. 


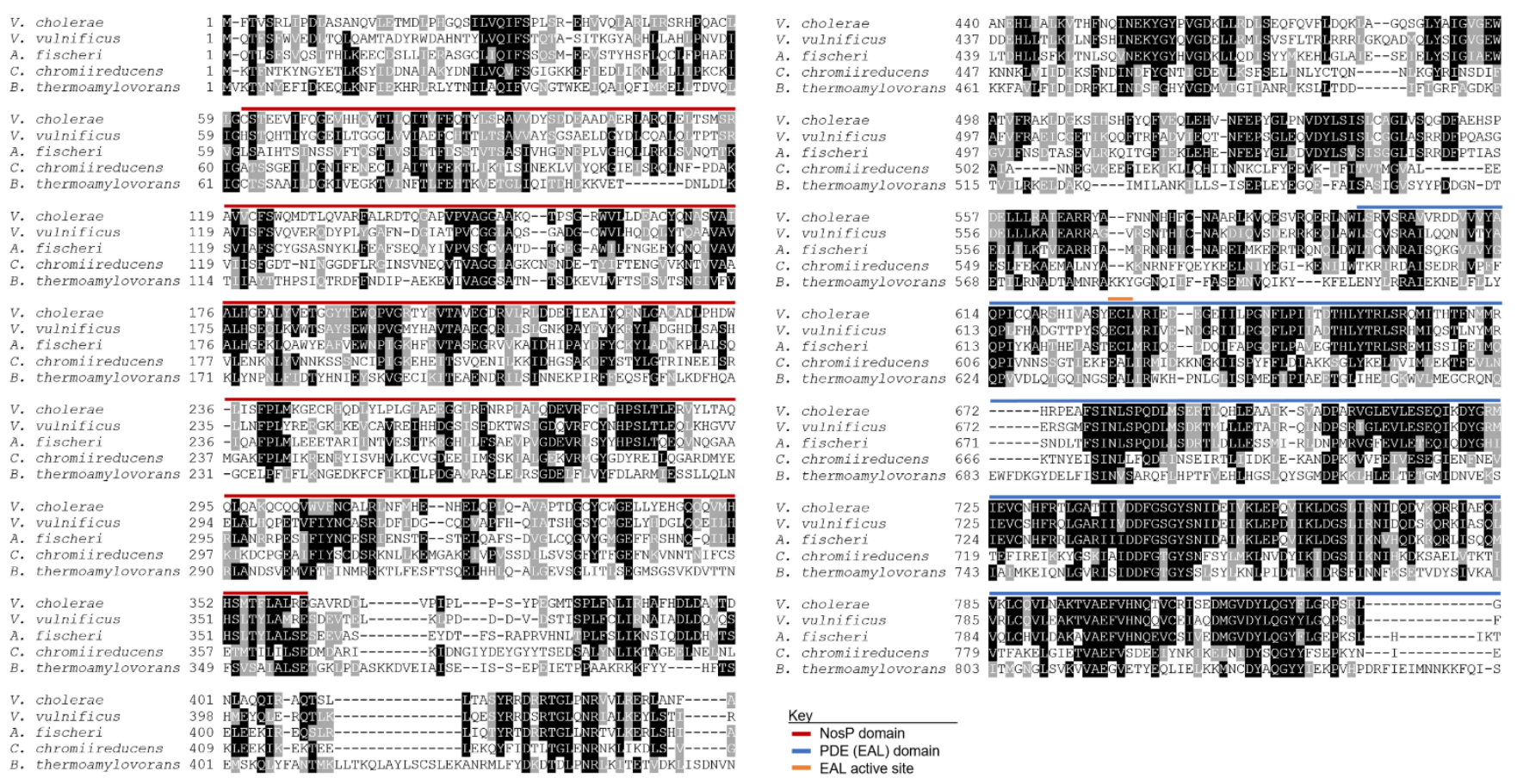

\section{Supplemental Figure 8: Alignment of CdpA homologs from different species.}

Multiple sequence alignment of CdpA homologs identified from V. cholerae, Vibrio vulnificus, Allivibrio fischeri, Clostridium chromiireducens, and Bacillus thremoamylovorans. The red line above the sequences denotes the NosP domain. The blue line above the sequences indicates the EAL domain responsible for PDE activity. The orange line marks the residues that give the EAL domain its name $(E C L$ in Vc CdpA). Residues highlighted in black are identical, while those highlighted in gray are similar. The GenBank Accession numbers used for the protein sequences are as follows: V. cholerae (QJS76791.1), V. vulnificus (WP_131070112.1), A. fischeri (WP_155689242.1), C. chromiireducens (WP_079439209.1), B. thermoamylovorans (WP_108897795.1). 
A

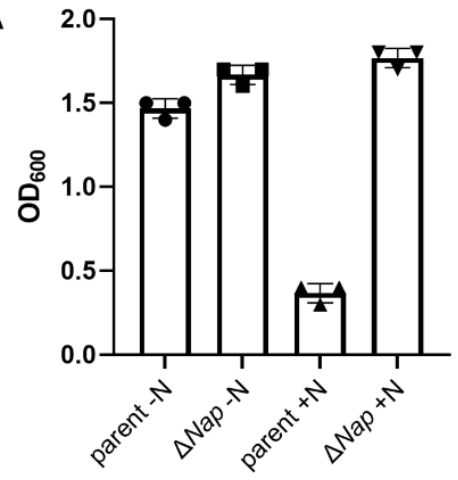

B

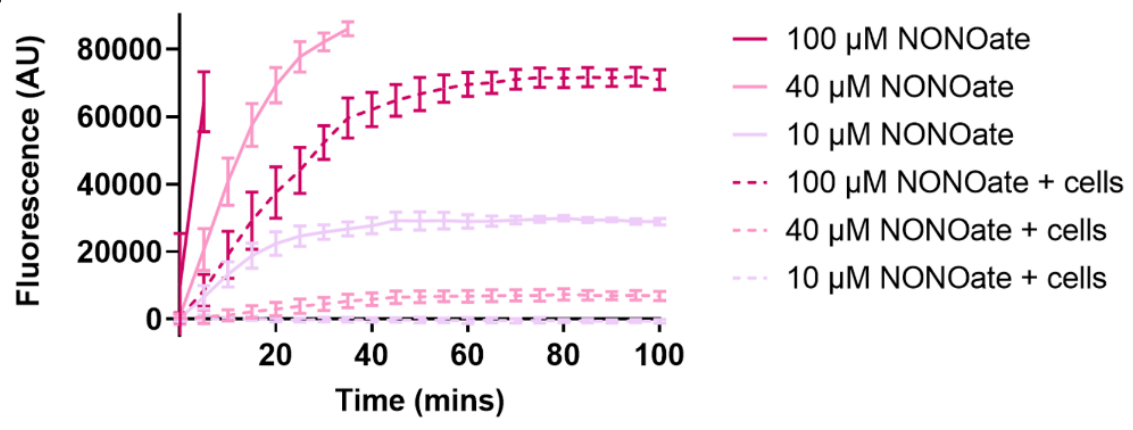

\section{Supplemental Figure 9: Validation of $\triangle$ Nap and DAR 4M-AM assays.}

(A) Microaerobic growth of parent and $\Delta N a p$ after $24 \mathrm{hr}$ in $\mathrm{M} 9+1 \%$ glucose either with $(+\mathrm{N})$ or without (N) $20 \mathrm{mM}$ nitrate. These results demonstrate that the parent grows poorly with added nitrate compared to the $\Delta$ Nap mutant, which is consistent with elevated levels of nitrite inhibiting bacterial growth in the parent as previously described ${ }^{39}$. This confirms that our $\Delta$ Nap mutant behaves as expected. (B) DAR 4M-AM measurement of NO released by DEA-NONOate either with (dashed lines) or without (solid lines) live bacterial cells present. Quantification of three biological replicates is shown in each graph and is displayed as the mean \pm SD. 


\section{Supplemental Movie 1: MSHA pilus retraction precedes detachment.}

Pilus retraction captured by epifluorescence time-lapse microscopy of AF488-mal labeled cells, as in Fig. 1A. The capture interval is $5 \mathrm{~s}$ between each frame. Scale bar $=1 \mu \mathrm{m}$.

\section{Supplemental Movie 2: Parent cells detach during MixD analysis.}

Time lapse of MixD assays of parent cells expressing either GFP (green) or mCherry (fuchsia), as in Fig. 1C. The capture interval is $1 \mathrm{~min}$ between each frame. Scale bar $=20 \mu \mathrm{m}$.

\section{Supplemental Movie 3: PilT-mCherry cells stay attached during MixD analysis}

Time lapse of MixD assays of PilT-mCherry cells expressing GFP (green) or parent cells expressing mCherry (fuchsia), as in Fig. 1D. The capture interval is $1 \mathrm{~min}$ between each frame. Scale bar $=20 \mu \mathrm{m}$.

\section{Supplemental Movie 4: PilT-mCherry attachment correlates with maintained pilus extension.}

Time lapse of pilus retraction captured by epifluorescence microscopy of AF488-mal labeled cells, as portrayed in Fig. 1E. Parent cells are distinguished by CyPet expression (blue). The capture interval is $5 \mathrm{~s}$ between each frame. Scale bar $=1 \mu \mathrm{m}$.

\section{Supplemental Movie 5: Aerobic GFP production only occurs at the edge of wells.}

Time lapse of a mixed culture of parent cells expressing mCherry (fuchsia) with $m s h E^{*}$ cells expressing CyPet (blue). The $m s h E^{*}$ also contains a $\mathrm{P}_{B A D}-g f p$ construct (top), which serves as a bioreporter for $\mathrm{O}_{2}$ in this experiment. Arabinose was added to the mixed culture immediately before imaging, as in Fig. 3B.

The capture interval is 5 mins between each frame. Scale bar $=20 \mu \mathrm{m}$.

\section{Supplemental Table 1: CdpA homologs found in eubacterial species.}

See attached file.

\section{Supplemental Table 2: Strain List}

\begin{tabular}{|c|c|c|c|c|}
\hline $\begin{array}{l}\text { Strain name in } \\
\text { manuscript }\end{array}$ & Figure & Genotype and antibiotic resistances & Strain \# & Reference \\
\hline Parent, V. cholerae & $\begin{array}{l}\text { Fig. 1A, 1B, 4C, } \\
\text { 5F, S1A, S2, } \\
\text { S4A, S4B, S4C, } \\
\text { S9A, SM1 }\end{array}$ & E7946 Sm ${ }^{\mathrm{R}}, \Delta \mathrm{VC} 1807:: \mathrm{Kan}^{\mathrm{R}}, \mathrm{msh} A \mathrm{T70C}$ & $\begin{array}{l}\text { CAH764 } \\
\text { (SAD3125) }\end{array}$ & $\begin{array}{l}\text { This study/ } \\
14,16\end{array}$ \\
\hline Parent & $\begin{array}{l}\text { Fig. } 1 C, 1 D, 2 A \\
2 B, 3 A, 3 B, 4 A \\
4 B, 5 B, 5 E, S 1 C\end{array}$ & 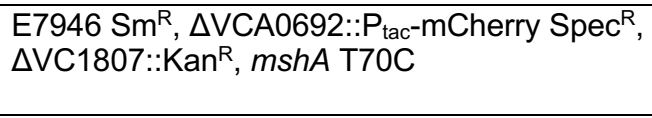 & $\begin{array}{l}\text { TND2274 } \\
\text { (SAD3126) }\end{array}$ & This study \\
\hline
\end{tabular}




\begin{tabular}{|c|c|c|c|c|}
\hline & $\begin{array}{l}\text { S3, S5B, S5C, } \\
\text { SM2, SM3, SM5 }\end{array}$ & & & \\
\hline Parent & Fig. 1C, 5A, SM2 & $\begin{array}{l}\text { E7946 SmR }, \Delta \text { VCA0692::P } \text { tac }^{R} \text { GFP Spec } \\
\Delta \text { VC1807::Kan }\end{array}$ & $\begin{array}{l}\text { TND2279 } \\
\text { (SAD3127) }\end{array}$ & This study \\
\hline pilT-mCherry & Fig. 1D, SM3 & 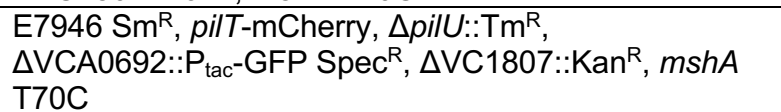 & $\begin{array}{l}\text { HKQ248 } \\
\text { (SAD3128) }\end{array}$ & This study \\
\hline Parent & $\begin{array}{l}\text { Fig. 1E, 2C, 2D, } \\
\text { 5C, SM4, }\end{array}$ & $\begin{array}{l}\text { E7946 SmR }, \Delta l a c Z:: P_{\text {tac }}-C y P e t \\
\Delta V C 1807:: K^{2}{ }^{R}, m s h A \text { T70C }\end{array}$ & $\begin{array}{l}\text { HKQ328 } \\
\text { (SAD3129) }\end{array}$ & This study \\
\hline pilT-mCherry & Fig. 1E, SM4 & 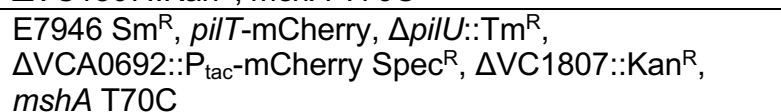 & $\begin{array}{l}\text { HKQ247 } \\
\text { (SAD3130) }\end{array}$ & This study \\
\hline $\mathrm{P}_{\mathrm{BAD}}-d c p A \Delta v p s$ & Fig. 2A, S1B & 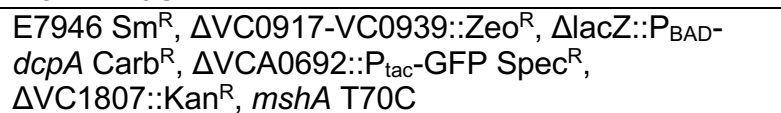 & $\begin{array}{l}\text { HKQ301 } \\
\text { (SAD3131) }\end{array}$ & This study \\
\hline$m s h E^{*}$ & $\begin{array}{l}\text { gDNA used to } \\
\text { amplify mshE } \\
\text { mutant construct }\end{array}$ & A1552 mshE L10A L54A L58A & SAD1748 & 20 \\
\hline$m s h E^{*}$ & Fig. 2B & $\begin{array}{l}\text { E7946 SmR }, \Delta V C A 0692:: P_{\text {tac-GFP Spec }} \text {, } \\
\Delta V C 1807:: \mathrm{Cm}^{\mathrm{R}}, \mathrm{mshE} \text { L10/54/58A, mshA T70C }\end{array}$ & $\begin{array}{l}\text { TND2277 } \\
\text { (SAD3132) }\end{array}$ & This study \\
\hline $\mathrm{P}_{\mathrm{BAD}}-d c p A \Delta v p s$ & Fig. 2C & 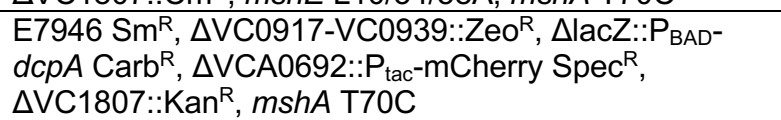 & $\begin{array}{l}\text { HKQ327 } \\
\text { (SAD3133) }\end{array}$ & This study \\
\hline$m s h E^{*}$ & Fig. 2D, 4C, S4A & $\begin{array}{l}\text { E7946 Sm }{ }^{\mathrm{R}}, m s h E \mathrm{~L} 10 / 54 / 58 \mathrm{~A}, \Delta \mathrm{VC} 1807:: \mathrm{Cm}^{\mathrm{R}}, m s h A \\
\text { T70C }\end{array}$ & SAD1756 & This study \\
\hline$m s h E^{*} P_{\mathrm{BAD}}-\mathrm{GFP}$ & Fig. 3B, SM5 & 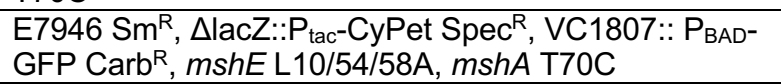 & $\begin{array}{l}\text { HKQ236 } \\
\text { (SAD3134) }\end{array}$ & This study \\
\hline$\Delta c d p A \Delta / a c Z:: c d p A$ & Fig. $4 \mathrm{~A}$ & 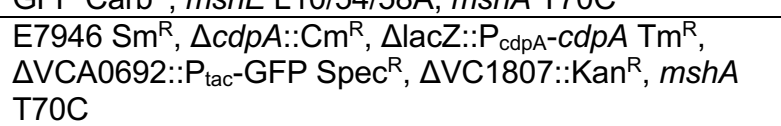 & $\begin{array}{l}\text { HKQ272 } \\
\text { (SAD3135) }\end{array}$ & This study \\
\hline $\begin{array}{l}\Delta c d p A \\
\triangle A A a C Z:: c d p A^{E C L} \rightarrow\end{array}$ & Fig. 4B & 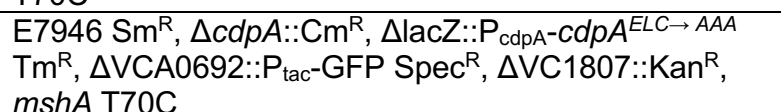 & $\begin{array}{l}\text { HKQ274 } \\
\text { (SAD3136) }\end{array}$ & This study \\
\hline$\Delta c d p A$ & Fig. $4 \mathrm{C}, 5 \mathrm{C}, \mathrm{S} 4 \mathrm{~A}$ & $\begin{array}{l}\text { E7946 Sm }{ }^{R}, \Delta c d p A:: \mathrm{Cm}^{\mathrm{R}}, \Delta \mathrm{VC} 1807:: \mathrm{Kan}^{\mathrm{R}}, \mathrm{msh} A \\
\text { T70C }\end{array}$ & $\begin{array}{l}\text { HKQ221 } \\
\text { (SAD3137) }\end{array}$ & This study \\
\hline$\Delta c d p A \Delta / a c Z:: c d p A$ & Fig. 4D & $\begin{array}{l}\text { E7946 Sm }{ }^{R}, \Delta c d p A:: \mathrm{Cm}^{R}, \Delta \text { lacZ:: } \mathrm{P}_{c d p A}-c d p A \mathrm{Spec}^{R}, \\
\text { delta VC1807::Kan +MshAT70C) }\end{array}$ & $\begin{array}{l}\text { HKQ230 } \\
\text { (SAD3138) }\end{array}$ & This study \\
\hline $\begin{array}{l}\Delta c d p A \\
\triangle l a c Z:: c d p A- \\
3 \times F L A G\end{array}$ & Fig. 4D & $\begin{array}{l}\text { E7946 SmR }, \Delta \text { lacZ::cdpA-3xFLAG Spec } \\
\text { AlacZ::: } \\
\text { T70C }\end{array}$ & $\begin{array}{l}\text { HKQ252 } \\
\text { (SAD3139) }\end{array}$ & This study \\
\hline$\triangle c d p A$ & Fig. 5A, 5B, S5B & $\begin{array}{l}\text { E7946 SmR } \mathrm{Sm}^{\mathrm{R}}, \Delta \mathrm{VA} 0692:: \mathrm{P}_{\mathrm{tac}}-\mathrm{GFP} \mathrm{Spec}^{\mathrm{R}}, \\
\Delta c d p A:: \mathrm{Cm}^{\mathrm{R}}, \Delta \mathrm{VC} 1807:: \mathrm{Kan}^{\mathrm{R}}, \mathrm{mshA} \mathrm{T70 \textrm {C }}\end{array}$ & $\begin{array}{l}\text { TND2276 } \\
\text { (SAD3140) }\end{array}$ & This study \\
\hline$\Delta N a p$ & Fig. 5E & 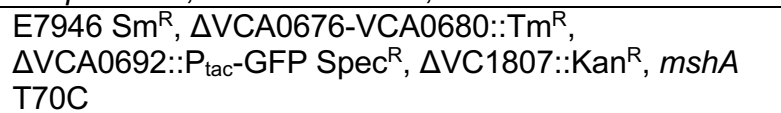 & $\begin{array}{l}\text { HKQ341 } \\
\text { (SAD3141) }\end{array}$ & This study \\
\hline E. coli & Fig. $5 \mathrm{~F}, \mathrm{~S} 9 \mathrm{~B}$ & MG1655 & SAD720 & 72 \\
\hline CdpA (purified) & Fig. 5D & E. coli BL21 (DE3), pET20b-cdpA-6xHis & $\mathrm{N} / \mathrm{A}$ & 25 \\
\hline Parent $\triangle \mathrm{MSHA}$ & Fig. S1A & $\begin{array}{l}\text { E7946 Sm }{ }^{R}, \Delta V C 0399-V C 0414:: \text { CarbR }^{R} \\
\Delta V C 1807:: K^{R}{ }^{R}\end{array}$ & SAD2592 & This study \\
\hline $\begin{array}{l}\mathrm{P}_{\mathrm{BAD}}-d c p A \Delta v p s \\
\Delta \mathrm{MSHA}\end{array}$ & Fig. S1B & 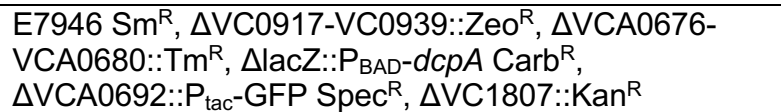 & $\begin{array}{l}\text { HKQ317 } \\
\text { (SAD3142) }\end{array}$ & This study \\
\hline$\Delta v p s$ & Fig. S1C & 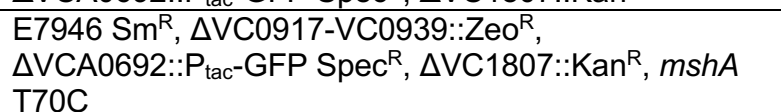 & $\begin{array}{l}\text { HKQ337 } \\
\text { (SAD3143) }\end{array}$ & This study \\
\hline$\Delta p$ ilT & Fig. S2 & E7946 Sm $, \Delta p i l T:: \mathrm{Tm}^{\mathrm{R}}, \Delta \mathrm{VC} 1807:: \mathrm{Kan}^{\mathrm{R}}, \mathrm{mshA} \mathrm{T} 70 \mathrm{C}$ & $\begin{array}{l}\text { HKQ001 } \\
\text { (SAD3144) }\end{array}$ & $\begin{array}{l}\text { This study/ } \\
16\end{array}$ \\
\hline pilT-mCherry & Fig. S2 & $\begin{array}{l}\text { E7946 SmR }{ }^{\mathrm{R}} \text { pilT-mCherry, } \triangle \mathrm{VC} 1807:: \mathrm{Spec}^{\mathrm{R}}, \mathrm{mshA} \\
\text { T70C }\end{array}$ & $\begin{array}{l}\text { TND1116 } \\
\text { (SAD3145) }\end{array}$ & This study \\
\hline
\end{tabular}




\begin{tabular}{|c|c|c|c|c|}
\hline$\triangle \mathrm{MSHA}$ & Fig. S3A, S3B & 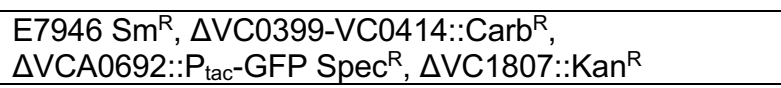 & $\begin{array}{l}\text { HKQ343 } \\
\text { (SAD3146) }\end{array}$ & This study \\
\hline $\mathrm{P}_{\mathrm{BAD}-}-c d g J$ & Fig. S3A, S3B & 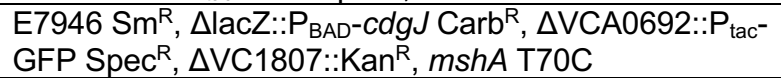 & $\begin{array}{l}\text { TND2335 } \\
\text { (SAD3147) }\end{array}$ & This study \\
\hline $\mathrm{P}_{\mathrm{BAD}-c d g J} m s h E^{*}$ & Fig. S3A, S3B & $\begin{array}{l}\text { E7946 Sm }{ }^{\mathrm{R}}, \Delta \mathrm{lacZ}:: \mathrm{P}_{\mathrm{BAD}}-c d g J \mathrm{Carb}^{\mathrm{R}}, \Delta \mathrm{VCA} 0692:: \mathrm{P}_{\mathrm{tac}}- \\
\text { GFP Spec }{ }^{\mathrm{R}}, m s h E \mathrm{~L} 10 / 54 / 58 \mathrm{~A}, \Delta \mathrm{V} C 1807:: \mathrm{Cm}^{\mathrm{R}}, m s h A \\
\text { T70C }\end{array}$ & $\begin{array}{l}\text { TND2334 } \\
\text { (SAD3148) }\end{array}$ & This study \\
\hline $\begin{array}{l}\Delta c d p A \\
\triangle l a c Z:: c d p A- \\
\text { 3xFLAG }\end{array}$ & Fig. S5C & 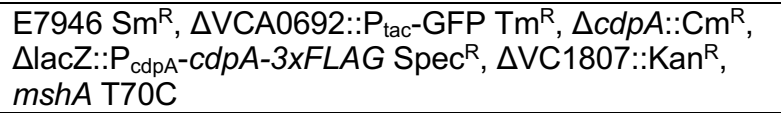 & $\begin{array}{l}\text { HKQ340 } \\
\text { (SAD3149) }\end{array}$ & This study \\
\hline$\Delta$ Nap & Fig. S9A & 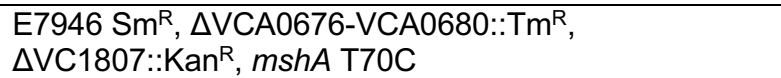 & $\begin{array}{l}\text { HKQ335 } \\
\text { (SAD3150) }\end{array}$ & This study \\
\hline
\end{tabular}

\section{Supplemental Table 3: Primer List}

\begin{tabular}{|c|c|c|}
\hline $\begin{array}{l}\text { Primer } \\
\text { name }\end{array}$ & Sequence $\left(5^{\prime} \rightarrow 3^{\prime}\right)$ & Description \\
\hline BBC1450 & CACTCAACGAGCTCAATACG & $m s h A$ T70C F1 \\
\hline BBC1453 & ATAGCCTTGCTGTTCATTTTGG & $m s h A$ T70C R2 \\
\hline BBC205 & $\begin{array}{l}\text { caatttcacacaggatcccgggAGGAGGTaacgtaATGGTGAGCAAGG } \\
\text { GCGAGG }\end{array}$ & $\mathrm{P}_{\text {tac}}-\mathrm{mCherry} \mathrm{Spec}^{R}$ insert $\mathrm{F}$ \\
\hline BBC206 & tgtaggctggagctgcttcTTACTTGTACAGCTCGTCCATG & $P_{\text {tac-mCherry } \text { Spec }^{R} \text { insert } R}$ \\
\hline BBC252 & $\begin{array}{l}\text { caatttcacacaggatcccgggAGGAGGTaacgtaATGCGTAAAGGAG } \\
\text { AAGAAC }\end{array}$ & $P_{\text {tac-GFP Spec }}{ }^{R}$ insert $F$ \\
\hline BBC254 & tgtaggctggagctgcttcTTAGTTGTATAGTTCATCCATGCC & $P_{\text {tac-GFP Spec }}{ }^{R}$ insert $R$ \\
\hline DOG0400 & ACTTCTGGCTGAAGGTCAATTTTC & pilT F1 \\
\hline BBC1932 & $\begin{array}{l}\text { TCCACCACTTCCACCtGCAAATGCTTTTAAATCCAACTCGAT } \\
T\end{array}$ & pilT-mCherry R1 \\
\hline BBC1835 & gcaggtggaagtggtggaGTGAGCAAGGGCGAGGAGG & mCherry (for pilT-mCherry) $\mathrm{F}$ \\
\hline BBC206 & tgtaggctggagctgcttcTTACTTGTACAGCTCGTCCATG & mCherry (for pilT-mCherry) $\mathrm{R}$ \\
\hline BBC2402 & gaagcagctccagcctacaAAAGCATTTTAGGTAGGTAAAGAC & pilT-mCherry F2 \\
\hline DOG0401 & gtcgacggatccccggaatCATTTAAATTCCTTAATAAAGTCTGGC & $\Delta p i l T:: \mathrm{Tm}^{\mathrm{R}} \mathrm{R} 1$ \\
\hline DOG0402 & gaagcagctccagcctacaTAGGTAGGTAAAGACAGATGGAG & $\Delta p i l T:: T^{R}{ }^{R} 2$ \\
\hline DOG0403 & TCACGTGTTCGGCCAAAATC & pilT R2 \\
\hline $\mathrm{BBC2381}$ & gtcgacggatccccggaatCAGATATTGATTCAACTCCATCTGTC & pilT-mCherry $\Delta$ pilU R1 \\
\hline DOG0406 & gaagcagctccagcctacaTAGCGATGGTTACTTTGTGCG & pilT-mCherry $\Delta$ pilU F2 \\
\hline BBC259 & $\begin{array}{l}\text { caatttcacacaggatcccgggAGGAGGTaacgtaATGGTGAGCAAGG } \\
\text { GAGAGG }\end{array}$ & $\mathrm{P}_{\text {tac }}$-CyPet Spec ${ }^{R}$ insert $F$ \\
\hline BBC261 & tgtaggctggagctgcttcTCATTTGTACAGTTCGTCCATG & $\mathrm{P}_{\text {tac }}-$ CyPet Spec ${ }^{R}$ insert $R$ \\
\hline BBC2022 & TGCCGATCTCGTTTATGGACG & $\Delta v p s(\mathrm{VC} 0917-\mathrm{VC} 0939):: \mathrm{Zeo}^{\mathrm{R}} \mathrm{F} 1$ \\
\hline BBC2023 & gtcgacggatccccggaatTGCCATTTTGATTGCCTCTGG & $\Delta v p s($ VC0917-VC0939)::Zeo R1 \\
\hline BBC2024 & gaagcagctccagcctacaCAAAGAGAGCCTTATTAGGCTCTC & $\Delta v p s(\mathrm{VC} 0917-\mathrm{VC} 0939):: Z e o^{R} \mathrm{~F} 2$ \\
\hline BBC2025 & TGAAAGAGGTTGCTCTAGAACTCG & $\Delta v p s$ (VC0917-VC0939)::Zeo R2 \\
\hline BBC753 & $\begin{array}{l}\text { atttcacacaggatcccgggAGGAGGTaacgtaATGGAATCTTATCTAA } \\
\text { GTAAAAAAGTC }\end{array}$ & $\mathrm{P}_{\mathrm{BAD}}-d c p A$ Carb $^{R}$ insert $\mathrm{F}$ \\
\hline BBC754 & tgtaggctggagctgcttcTTAAGTCTCACTCATACCTGACAG & $\mathrm{P}_{\mathrm{BAD}}-d c p A$ Carb $^{R}$ insert $\mathrm{R}$ \\
\hline ABD648 & AACTAAGCTGCTGCAGATTGTC & $m s h E^{*} \mathrm{~F} 1$ \\
\hline DOG0420 & TGTGTAGTCTAACGTTTCAATGC & $m s h E^{*} \mathrm{R} 2$ \\
\hline HQP0187 & CATTACCGCATTTTCAATGC & $\Delta c d p A:: \mathrm{Cm}^{\mathrm{R}} \mathrm{F} 1$ \\
\hline HQP0188 & gtcgacggatccccggaatCATAAAGAGCTGATAAGCCAGTG & $\Delta c d p A:: \mathrm{Cm}^{\mathrm{R}} \mathrm{R} 1$ \\
\hline HQP0189 & gaagcagctccagcctacaTAACGCAAGATAGACGCGTC & $\Delta c d p A:: \mathrm{Cm}^{\mathrm{R}} \mathrm{F} 2$ \\
\hline HQP0190 & GAGTGCATGACCAGAATGAC & $\Delta c d p A:: \mathrm{Cm}^{\mathrm{R}} \mathrm{R} 2$ \\
\hline HQP0209 & GCCTGGGGTGCCTAATGAGTCGAGCGTCTCTCGGAATTAC & $\mathrm{P}_{\mathrm{cdpA}}-c d p A \mathrm{Tm}^{\mathrm{R}}$ insert $\mathrm{F}$ \\
\hline
\end{tabular}




\begin{tabular}{|c|c|c|}
\hline HQP0210 & tgtaggctggagctgcttcTTAACCCAAGCGTGAAGGTCG & $\mathrm{P}_{\mathrm{cdpA}}-c d p A \mathrm{Tm}^{\mathrm{R}}$ insert $\mathrm{R}$ \\
\hline HQP0257 & $\begin{array}{l}\text { TTCATCTTCAATCCGCACagccgcggCGTAGGAAGCCACAATG } \\
\text { TG }\end{array}$ & $c d p A^{E C L \rightarrow A A A} \mathrm{R} 1$ \\
\hline HQP0258 & $\begin{array}{l}\text { CACATTGTGGCTTCCTACGccgcggctGTGCGGATTGAAGATG } \\
\text { AA }\end{array}$ & $c d p A^{E C L \rightarrow A A A} \mathrm{~F} 2$ \\
\hline HQP0207 & tccaccacttccacctgcACCCAAGCGTGAAGGTCG & cdpA-3xFLAG R1 \\
\hline BBC2272 & $\begin{array}{l}\text { gcaggtggaagtggtggagattataaagaccatgatggtgactacaa } \\
\text { ggatcacgacattgattataaggatgacgatgacaaagcaggtggagcaggtgga }\end{array}$ & 3xFLAG F \\
\hline BBC2273 & $\begin{array}{l}\text { tccacctgctccacctgctttgtcatcgtcatccttataatcaatgtcgtgat } \\
\text { ccttgtagtcaccatcatggtctttataatctccaccacttccacctgc }\end{array}$ & 3xFLAG R \\
\hline HQP0208 & gcaggtggagcaggtggaTAACGCAAGATAGACGCGTC & cdpA-3xFLAG F2 \\
\hline HQP0286 & ACATCAAGCAGGTGCTCAATC & $\Delta$ Nap (VCA0676-VCA0680)::TmR F1 \\
\hline HQP0287 & gtcgacggatccccggaatCACACCTGTTCACAACCTGC & $\Delta$ Nap (VCA0676-VCA0680)::TmR R1 \\
\hline HQP0288 & gaagcagctccagcctacaTAAGGAGAGCCACTATGAGTAC & $\Delta$ Nap (VCA0676-VCA0680)::TmR F2 \\
\hline HQP0289 & CAGCAGCTCTTGATCCGAAG & $\Delta$ Nap (VCA0676-VCA0680):: $\mathrm{Tm}^{\mathrm{R}} \mathrm{R} 2$ \\
\hline DOG0436 & AAGCGTTCTGGTTCAATCACC & $\Delta \mathrm{MSHA}(\mathrm{VC} 0399-\mathrm{VC} 0414):: \mathrm{Carb}^{R} \mathrm{F1}$ \\
\hline DOG0434 & gtcgacggatccccggaatCATTCTCTACCACTGCTATTTGGTTC & 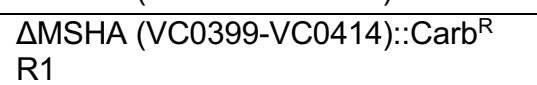 \\
\hline BBC2129 & gaagcagctccagcctacaTAATGATTAAGCACTCAATGGATCCAG & $\triangle \mathrm{MSHA}(\mathrm{VC} 0399-\mathrm{VC} 0414):: \mathrm{Carb}^{R} \mathrm{F2}$ \\
\hline BBC2130 & TTTTGCATCAGCAAAATCACGC & 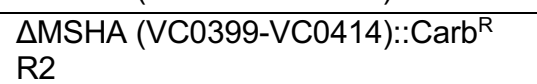 \\
\hline BBC755 & $\begin{array}{l}\text { caatttcacacaggatccogggAGGAGGTaacgtaATGTACACAACTTA } \\
\text { TGTAGCACG }\end{array}$ & $\mathrm{P}_{\mathrm{BAD}}-$ cdgJ Carb $^{\mathrm{R}}$ insert $\mathrm{F}$ \\
\hline BBC756 & tgtaggctggagctgcttcCTAAATTAATCGATTGATGTCCTGG & $\mathrm{P}_{\mathrm{BAD}-c d g J}$ Carb $^{R}$ insert $\mathrm{R}$ \\
\hline
\end{tabular}

\section{Supplemental Table 4: Mean values for each data set}

\begin{tabular}{|c|c|c|c|c|c|}
\hline Figure & Strain name & Mean & Figure & Strain name & Mean \\
\hline Fig. 1C & Parent (green), time $=0$ & $1.00 \mathrm{E}+00$ & Fig. 5E & $\Delta$ Nap, time $=2$ & $2.43 E-01$ \\
\hline Fig. 1C & Parent (green), time $=1$ & $6.59 \mathrm{E}-01$ & Fig. 5E & $\Delta$ Nap, time $=3$ & 1.39E-01 \\
\hline Fig. 1C & Parent (green), time $=2$ & $3.42 \mathrm{E}-01$ & Fig. 5E & $\Delta$ Nap, time $=4$ & 8.95E-02 \\
\hline Fig. 1C & Parent (green), time $=3$ & 1.99E-01 & Fig. 5E & $\Delta$ Nap, time $=5$ & 7.16E-02 \\
\hline Fig. 1C & Parent (green), time $=4$ & $1.30 \mathrm{E}-01$ & Fig. $5 \mathrm{E}$ & $\Delta$ Nap, time $=6$ & $5.00 \mathrm{E}-02$ \\
\hline Fig. 1C & Parent (green), time $=5$ & $1.24 \mathrm{E}-01$ & Fig. 5E & Parent, time $=0$ & $1.00 \mathrm{E}+00$ \\
\hline Fig. 1C & Parent (green), time $=6$ & 8.96E-02 & Fig. 5E & Parent, time $=1$ & 7.34E-01 \\
\hline Fig. 1C & Parent (fuchsia), time $=0$ & $1.00 \mathrm{E}+00$ & Fig. 5E & Parent, time $=2$ & $3.31 \mathrm{E}-01$ \\
\hline Fig. 1C & Parent (fuchsia), time $=1$ & $6.14 \mathrm{E}-01$ & Fig. 5E & Parent, time $=3$ & $1.92 \mathrm{E}-01$ \\
\hline Fig. 1C & Parent (fuchsia), time $=2$ & 2.69E-01 & Fig. 5E & Parent, time $=4$ & $1.00 \mathrm{E}-01$ \\
\hline Fig. 1C & Parent (fuchsia), time $=3$ & $1.22 \mathrm{E}-01$ & Fig. 5E & Parent, time $=5$ & 7.24E-02 \\
\hline Fig. 1C & Parent (fuchsia), time $=4$ & $8.78 \mathrm{E}-02$ & Fig. 5E & Parent, time $=6$ & $6.66 \mathrm{E}-02$ \\
\hline Fig. 1C & Parent (fuchsia), time $=5$ & 7.74E-02 & Fig. S1C & $\Delta v p s$, time $=0$ & $1.00 \mathrm{E}+00$ \\
\hline Fig. 1C & Parent (fuchsia), time $=6$ & 6.29E-02 & Fig. S1C & $\Delta v p s$, time $=1$ & $5.72 \mathrm{E}-01$ \\
\hline Fig. 1D & pilT-mCherry, time $=0$ & $1.00 \mathrm{E}+00$ & Fig. S1C & $\Delta v p s$, time $=2$ & $2.10 \mathrm{E}-01$ \\
\hline Fig. 1D & pilT-mCherry, time $=1$ & $1.04 \mathrm{E}+00$ & Fig. S1C & $\Delta v p s$, time $=3$ & $1.13 \mathrm{E}-01$ \\
\hline Fig. 1D & pilT-mCherry, time $=2$ & $1.06 \mathrm{E}+00$ & Fig. S1C & $\Delta v p s$, time $=4$ & 4.75E-02 \\
\hline Fig. 1D & pilT-mCherry, time $=3$ & $1.07 E+00$ & Fig. S1C & $\Delta v p s$, time $=5$ & 3.35E-02 \\
\hline Fig. 1D & pilT-mCherry, time $=4$ & $1.09 \mathrm{E}+00$ & Fig. S1C & $\Delta v p s$, time $=6$ & $2.83 \mathrm{E}-02$ \\
\hline Fig. 1D & pilT-mCherry, time $=5$ & $1.10 \mathrm{E}+00$ & Fig. S1C & Parent, time $=0$ & $1.00 \mathrm{E}+00$ \\
\hline Fig. 1D & pilT-mCherry, time $=6$ & $1.09 \mathrm{E}+00$ & Fig. S1C & Parent, time $=1$ & 6.37E-01 \\
\hline Fig. 1D & Parent, time $=0$ & $1.00 \mathrm{E}+00$ & Fig. S1C & Parent, time $=2$ & 3.26E-01 \\
\hline Fig. 1D & Parent, time $=1$ & $7.26 \mathrm{E}-01$ & Fig. S1C & Parent, time $=3$ & $1.21 \mathrm{E}-01$ \\
\hline
\end{tabular}




\begin{tabular}{|c|c|c|c|c|c|}
\hline Fig. 1D & Parent, time $=2$ & $4.64 \mathrm{E}-01$ & Fig. S1C & Parent, time $=4$ & $6.42 \mathrm{E}-02$ \\
\hline Fig. 1D & Parent, time $=3$ & $2.78 \mathrm{E}-01$ & Fig. S1C & Parent, time $=5$ & $5.51 \mathrm{E}-02$ \\
\hline Fig. 1D & Parent, time $=4$ & 1.93E-01 & Fig. S1C & Parent, time $=6$ & $5.80 \mathrm{E}-02$ \\
\hline Fig. 1D & Parent, time $=5$ & $1.25 \mathrm{E}-01$ & Fig. S3 & $\mathrm{P}_{\mathrm{BAD}-c d g J}$ & 7.95E-02 \\
\hline Fig. 1D & Parent, time $=6$ & $9.31 \mathrm{E}-02$ & Fig. S3 & $\mathrm{P}_{\mathrm{BAD}-c d g J, m s h E^{*}}$ & $1.76 \mathrm{E}+00$ \\
\hline Fig. 2A & $P_{B A D^{-}} d c p A \Delta v p s$, time $=0$ & $1.00 \mathrm{E}+00$ & Fig. S3 & $\triangle \mathrm{MSHA}$ & $8.05 \mathrm{E}-03$ \\
\hline Fig. 2A & $P_{B A D}-d c p A \Delta v p s$, time $=1$ & $1.18 \mathrm{E}+00$ & Fig. S4A & Parent, aerobic & 1.32E-02 \\
\hline Fig. $2 \mathrm{~A}$ & $P_{B A D}-d c p A \Delta v p s$, time $=2$ & $1.29 \mathrm{E}+00$ & Fig. S4A & Parent, microaerobic & 1.17E-04 \\
\hline Fig. 2A & $P_{B A D}-d c p A \Delta v p s$, time $=3$ & $1.36 \mathrm{E}+00$ & Fig. S4A & MshE $^{*}$, aerobic & $5.12 \mathrm{E}-03$ \\
\hline Fig. 2A & $P_{B A D}-d c p A \Delta v p s$, time $=4$ & $1.40 \mathrm{E}+00$ & Fig. S4A & MshE $^{*}$, microaerobic & 1.89E-02 \\
\hline Fig. $2 \mathrm{~A}$ & $P_{B A D}-d c p A \Delta v p s$, time $=5$ & $1.45 \mathrm{E}+00$ & Fig. S4A & $\Delta c d p A$, aerobic & $1.78 \mathrm{E}-02$ \\
\hline Fig. $2 \mathrm{~A}$ & $P_{B A D}-d c p A \Delta v p s$, time $=6$ & $1.48 \mathrm{E}+00$ & Fig. S4A & $\Delta c d p A$, microaerobic & 7.12E-03 \\
\hline Fig. 2A & Parent, time $=0$ & $1.00 \mathrm{E}+00$ & Fig. S4B & + air, - culture & $2.25 \mathrm{E}+01$ \\
\hline Fig. 2A & Parent, time $=1$ & 7.49E-01 & Fig. S4B & - air, - culture & $6.73 \mathrm{E}-01$ \\
\hline Fig. $2 \mathrm{~A}$ & Parent, time $=2$ & $3.28 \mathrm{E}-01$ & Fig. S4B & + air, + culture & $1.38 \mathrm{E}+01$ \\
\hline Fig. $2 \mathrm{~A}$ & Parent, time $=3$ & $1.58 \mathrm{E}-01$ & Fig. S4B & - air, + culture & $6.55 \mathrm{E}-01$ \\
\hline Fig. 2A & Parent, time $=4$ & 8.90E-02 & Fig. S4C & 5 seconds & $1.35 \mathrm{E}+01$ \\
\hline Fig. 2A & Parent, time $=5$ & 5.34E-02 & Fig. S4C & 10 seconds & $1.12 \mathrm{E}+01$ \\
\hline Fig. $2 \mathrm{~A}$ & Parent, time $=6$ & 6.41E-02 & Fig. S4C & 15 seconds & $1.00 \mathrm{E}+01$ \\
\hline Fig. 2B & $m s h E^{*}$, time $=0$ & $1.00 \mathrm{E}+00$ & Fig. S4C & 20 seconds & $9.00 \mathrm{E}+00$ \\
\hline Fig. 2B & $m s h E^{*}$, time $=1$ & $1.12 \mathrm{E}+00$ & Fig. S4C & 25 seconds & $8.23 E+00$ \\
\hline Fig. 2B & $m s h E^{*}$, time $=2$ & $1.13 \mathrm{E}+00$ & Fig. S4C & 30 seconds & $7.53 \mathrm{E}+00$ \\
\hline Fig. 2B & $m s h E^{*}$, time $=3$ & $1.10 \mathrm{E}+00$ & Fig. S4C & 35 seconds & $6.68 \mathrm{E}+00$ \\
\hline Fig. 2B & $m s h E^{*}$, time $=4$ & $1.08 \mathrm{E}+00$ & Fig. S4C & 40 seconds & $5.98 \mathrm{E}+00$ \\
\hline Fig. 2B & $m s h E^{*}$, time $=5$ & $1.12 \mathrm{E}+00$ & Fig. S4C & 45 seconds & $5.43 E+00$ \\
\hline Fig. 2B & $m s h E^{*}$, time $=6$ & $1.14 \mathrm{E}+00$ & Fig. S4C & 50 seconds & $4.60 \mathrm{E}+00$ \\
\hline Fig. 2B & Parent, time $=0$ & $1.00 \mathrm{E}+00$ & Fig. S4C & 55 seconds & $4.15 \mathrm{E}+00$ \\
\hline Fig. 2B & Parent, time $=1$ & 8.82E-01 & Fig. S4C & 60 seconds & $3.68 \mathrm{E}+00$ \\
\hline Fig. 2B & Parent, time $=2$ & $5.76 \mathrm{E}-01$ & Fig. S4C & 65 seconds & $2.85 \mathrm{E}+00$ \\
\hline Fig. 2B & Parent, time $=3$ & $3.41 \mathrm{E}-01$ & Fig. S4C & 70 seconds & $2.12 \mathrm{E}+00$ \\
\hline Fig. 2B & Parent, time $=4$ & $2.38 \mathrm{E}-01$ & Fig. S4C & 75 seconds & $1.59 \mathrm{E}+00$ \\
\hline Fig. 2B & Parent, time $=5$ & 1.65E-01 & Fig. S4C & 80 seconds & $1.13 \mathrm{E}+00$ \\
\hline Fig. 2B & Parent, time $=6$ & 9.67E-02 & Fig. S4C & 85 seconds & $9.15 \mathrm{E}-01$ \\
\hline Fig. 4A & $\Delta c d p A, \Delta l a c Z:: c d p A$, time $=0$ & $1.00 \mathrm{E}+00$ & Fig. S4C & 90 seconds & $8.15 \mathrm{E}-01$ \\
\hline Fig. 4A & $\Delta c d p A, \Delta / a c Z:: c d p A$, time $=1$ & 7.73E-01 & Fig. S4C & 95 seconds & $9.85 \mathrm{E}-01$ \\
\hline Fig. 4A & $\Delta c d p A, \Delta / a c Z:: c d p A$, time $=2$ & 3.37E-01 & Fig. S4C & 100 seconds & 7.33E-01 \\
\hline Fig. 4A & $\Delta c d p A, \Delta / a c Z:: c d p A$, time $=3$ & $1.76 \mathrm{E}-01$ & Fig. S4C & 105 seconds & $7.13 \mathrm{E}-01$ \\
\hline Fig. 4A & $\Delta c d p A, \Delta / a c Z:: c d p A$, time $=4$ & $1.01 \mathrm{E}-01$ & Fig. S4C & 110 seconds & $6.85 \mathrm{E}-01$ \\
\hline Fig. 4A & $\Delta c d p A, \Delta / a c Z:: c d p A$, time $=5$ & $6.91 \mathrm{E}-02$ & Fig. S4C & 115 seconds & $6.90 \mathrm{E}-01$ \\
\hline Fig. 4A & $\Delta c d p A, \Delta / a c Z:: c d p A$, time $=6$ & $8.21 \mathrm{E}-02$ & Fig. S4C & 120 seconds & $6.80 \mathrm{E}-0$ \\
\hline Fig. 4A & Parent, time $=0$ & $1.00 \mathrm{E}+00$ & Fig. S5B & $\Delta c d p A$, time $=0$ & $1.00 \mathrm{E}+00$ \\
\hline Fig. 4A & Parent, time $=1$ & $7.08 \mathrm{E}-01$ & Fig. S5B & $\Delta c d p A$, time $=1$ & $1.01 \mathrm{E}+00$ \\
\hline Fig. 4A & Parent, time $=2$ & $2.59 \mathrm{E}-01$ & Fig. S5B & $\Delta c d p A$, time $=2$ & $1.02 \mathrm{E}+00$ \\
\hline Fig. 4A & Parent, time $=3$ & $1.11 \mathrm{E}-01$ & Fig. S5B & $\Delta c d p A$, time $=3$ & $1.05 \mathrm{E}+00$ \\
\hline Fig. 4A & Parent, time $=4$ & 7.49E-01 & Fig. S5B & $\Delta c d p A$, time $=4$ & 9.87E-01 \\
\hline Fig. 4A & Parent, time $=5$ & 6.36E-01 & Fig. S5B & $\Delta c d p A$, time $=5$ & 8.33E-01 \\
\hline Fig. 4A & Parent, time $=6$ & 3.77E-01 & Fig. S5B & $\Delta c d p A$, time $=6$ & 7.41E-01 \\
\hline Fig. 4B & $\Delta c d p A, \Delta / a c Z:: c d p A^{E C L \rightarrow A A A}$, time $=0$ & $1.00 \mathrm{E}+00$ & Fig. S5B & $\Delta c d p A$, time $=7$ & 6.97E-01 \\
\hline Fig. 4B & $\Delta c d p A, \Delta / a c Z:: c d p A^{E C L \rightarrow A A A}$, time $=1$ & $1.10 \mathrm{E}+00$ & Fig. S5B & $\Delta c d p A$, time $=8$ & $6.52 \mathrm{E}-01$ \\
\hline
\end{tabular}




\begin{tabular}{|c|c|c|c|c|c|}
\hline Fig. 4B & $\Delta c d p A, \Delta l a c Z:: c d p A^{E C L \rightarrow A A A}$, time $=2$ & $1.14 \mathrm{E}+00$ & Fig. S5B & $\Delta c d p A$, time $=9$ & $5.96 \mathrm{E}-01$ \\
\hline Fig. 4B & $\Delta c d p A, \Delta / a c Z:: c d p A^{E C L \rightarrow A A A}$, time $=3$ & $1.16 \mathrm{E}+00$ & Fig. S5B & $\Delta c d p A$, time $=10$ & $5.98 \mathrm{E}-01$ \\
\hline Fig. 4B & $\Delta c d p A, \Delta / a c Z:: c d p A^{E C L \rightarrow A A A}$, time $=4$ & $1.09 \mathrm{E}+00$ & Fig. S5B & $\Delta c d p A$, time $=11$ & 5.43E-01 \\
\hline Fig. 4B & $\Delta c d p A, \triangle l a c Z:: c d p A^{E C L \rightarrow A A A}$, time $=5$ & $1.05 \mathrm{E}+00$ & Fig. S5B & $\Delta c d p A$, time $=12$ & $5.14 \mathrm{E}-01$ \\
\hline Fig. 4B & $\Delta c d p A, \Delta l a c Z:: c d p A^{E C L \rightarrow A A A}$, time $=6$ & $1.03 \mathrm{E}+00$ & Fig. S5B & Parent, time $=0$ & $1.00 \mathrm{E}+00$ \\
\hline Fig. 4B & Parent, time $=0$ & $1.00 \mathrm{E}+00$ & Fig. S5B & Parent, time $=1$ & $9.10 \mathrm{E}-01$ \\
\hline Fig. 4B & Parent, time $=1$ & $6.75 \mathrm{E}-01$ & Fig. S5B & Parent, time $=2$ & $6.32 \mathrm{E}-01$ \\
\hline Fig. 4B & Parent, time $=2$ & 3.84E-01 & Fig. S5B & Parent, time $=3$ & 3.14E-01 \\
\hline Fig. 4B & Parent, time $=3$ & $1.50 \mathrm{E}-01$ & Fig. S5B & Parent, time $=4$ & 1.97E-01 \\
\hline Fig. 4B & Parent, time $=4$ & 1.17E-01 & Fig. S5B & Parent, time $=5$ & 1.14E-01 \\
\hline Fig. 4B & Parent, time $=5$ & 1.35E-01 & Fig. S5B & Parent, time $=6$ & 9.03E-02 \\
\hline Fig. 4B & Parent, time $=6$ & 1.11E-01 & Fig. S5B & Parent, time $=7$ & 5.99E-02 \\
\hline Fig. 4C & Parent, aerobic & $1.08 \mathrm{E}+01$ & Fig. S5B & Parent, time $=8$ & 7.13E-02 \\
\hline Fig. 4C & Parent, microaerobic & $4.11 \mathrm{E}+00$ & Fig. S5B & Parent, time $=9$ & 6.07E-02 \\
\hline Fig. 4C & MshE* $^{*}$ aerobic & $9.21 \mathrm{E}+00$ & Fig. S5B & Parent, time $=10$ & 5.96E-02 \\
\hline Fig. 4C & MshE $^{*}$, microaerobic & $3.81 \mathrm{E}+00$ & Fig. S5B & Parent, time $=11$ & 5.34E-02 \\
\hline Fig. 4C & $\Delta c d p A$, aerobic & $1.23 \mathrm{E}+01$ & Fig. S5B & Parent, time $=12$ & 4.68E-02 \\
\hline Fig. 4C & $\Delta c d p A$, microaerobic & $1.03 \mathrm{E}+01$ & Fig. S5C & $\Delta c d p A \Delta / a c Z:: c d p A-3 x F L A G$, time $=0$ & $1.00 \mathrm{E}+00$ \\
\hline Fig. 4D & Total CdpA, aerobic & 2.11E-01 & Fig. S5C & $\Delta c d p A \Delta / a c Z:: c d p A-3 x F L A G$, time $=1$ & 7.02E-01 \\
\hline Fig. 4D & Total CdpA, microaerobic & $4.20 \mathrm{E}-01$ & Fig. S5C & $\Delta c d p A \Delta / a c Z:: c d p A-3 x F L A G$, time $=2$ & $3.21 \mathrm{E}-01$ \\
\hline Fig. 4D & Upper band, aerobic & 3.52E-02 & Fig. S5C & $\triangle c d p A \Delta / a c Z:: c d p A-3 x F L A G$, time $=3$ & $1.54 \mathrm{E}-01$ \\
\hline Fig. 4D & Upper band, microaerobic & $1.23 \mathrm{E}-01$ & Fig. S5C & $\Delta c d p A \Delta / a c Z:: c d p A-3 x F L A G$, time $=4$ & 1.13E-01 \\
\hline Fig. 4D & Lower band, aerobic & $1.58 \mathrm{E}-01$ & Fig. S5C & $\Delta c d p A \Delta / a c Z:: c d p A-3 x F L A G$, time $=5$ & 6.35E-02 \\
\hline Fig. 4D & Lower band, microaerobic & $2.72 \mathrm{E}-01$ & Fig. S5C & $\Delta c d p A \Delta / a c Z:: c d p A-3 x F L A G$, time $=6$ & $3.38 \mathrm{E}-02$ \\
\hline Fig. 5B & $\Delta c d p A$ - NONOate & $6.30 \mathrm{E}-01$ & Fig. S5C & Parent, time $=0$ & $1.00 \mathrm{E}+00$ \\
\hline Fig. 5B & $\Delta c d p A+$ NONOate & $1.03 \mathrm{E}-01$ & Fig. S5C & Parent, time $=1$ & $6.58 \mathrm{E}-01$ \\
\hline Fig. 5C & $\Delta c d p A$ - NONOate & $1.00 \mathrm{E}+00$ & Fig. S5C & Parent, time $=2$ & $3.20 \mathrm{E}-01$ \\
\hline Fig. 5C & parent - NONOate & 8.27E-01 & Fig. S5C & Parent, time $=3$ & $1.70 \mathrm{E}-01$ \\
\hline Fig. 5C & $\Delta c d p A+$ NONOate & 9.33E-01 & Fig. S5C & Parent, time $=4$ & 9.93E-02 \\
\hline Fig. 5C & parent + NONOate & 8.00E-02 & Fig. S5C & Parent, time $=5$ & $5.72 \mathrm{E}-02$ \\
\hline Fig. 5E & $\Delta$ Nap, time $=0$ & $1.00 \mathrm{E}+00$ & Fig. S5C & Parent, time $=6$ & $4.86 \mathrm{E}-02$ \\
\hline Fig. 5E & $\Delta$ Nap, time $=1$ & $5.88 \mathrm{E}-01$ & & & \\
\hline
\end{tabular}

\section{Supplemental Table 5: Statistical Comparisons}

\begin{tabular}{|l|c|c|l|}
\hline Comparison & \multicolumn{2}{|c|}{ P-value } & Figure \\
\hline parent (green) vs. parent (fuchsia), $\mathrm{t}=0$ & $\mathrm{~ns}$ & $>0.9999$ & Fig. 1C \\
\hline parent (green) vs. parent (fuchsia), $\mathrm{t}=1$ & $\mathrm{~ns}$ & 0.9721 & Fig. 1C \\
\hline parent (green) vs. parent (fuchsia), $\mathrm{t}=2$ & $\mathrm{~ns}$ & 0.8493 & Fig. 1C \\
\hline parent (green) vs. parent (fuchsia), $\mathrm{t}=3$ & $\mathrm{~ns}$ & 0.6449 & Fig. 1C \\
\hline parent (green) vs. parent (fuchsia), $\mathrm{t}=4$ & $\mathrm{~ns}$ & 0.8493 & Fig. 1C \\
\hline parent (green) vs. parent (fuchsia), $\mathrm{t}=5$ & $\mathrm{~ns}$ & 0.7254 & Fig. 1C \\
\hline parent (green) vs. parent (fuchsia), $\mathrm{t}=6$ & $\mathrm{~ns}$ & 0.8493 & Fig. 1C \\
\hline pilT-mCherry vs. parent, $\mathrm{t}=0$ & $\mathrm{~ns}$ & $>0.9999$ & Fig. 1D \\
\hline pilT-mCherry vs. parent, $\mathrm{t}=1$ & $\mathrm{~ns}$ & 0.4549 & Fig. 1D \\
\hline pilT-mCherry vs. parent, $\mathrm{t}=2$ & ${ }^{*}$ & 0.0380 & Fig. 1D \\
\hline pilT-mCherry vs. parent, $\mathrm{t}=3$ & ${ }^{* * *}$ & 0.0005 & Fig. 1D \\
\hline pilT-mCherry vs. parent, $\mathrm{t}=4$ & ${ }^{* * * *}$ & $<0.0001$ & Fig. 1D \\
\hline
\end{tabular}




\begin{tabular}{|c|c|c|c|}
\hline pilT-mCherry vs. parent, $\mathrm{t}=5$ & $* * * *$ & $<0.0001$ & Fig. 1D \\
\hline pilT-mCherry vs. parent, $\mathrm{t}=6$ & $* * * *$ & $<0.0001$ & Fig. 1D \\
\hline$P_{B A D}-d c p A \triangle v p s$ vs. parent, $\mathrm{t}=0$ & ns & $>0.9999$ & Fig. 2A \\
\hline$P_{B A D}-d c p A \triangle v p s$ vs. parent, $\mathrm{t}=1$ & ns & 0.2476 & Fig. 2A \\
\hline$P_{B A D}-d c p A \triangle v p s$ vs. parent, $\mathrm{t}=2$ & *** & 0.0001 & Fig. 2A \\
\hline$P_{B A D}-d c p A \triangle v p s$ vs. parent, $\mathrm{t}=3$ & $* * * *$ & $<0.0001$ & Fig. $2 \mathrm{~A}$ \\
\hline$P_{B A D}-d c p A \triangle v p s$ vs. parent, $\mathrm{t}=4$ & $* * * *$ & $<0.0001$ & Fig. $2 \mathrm{~A}$ \\
\hline$P_{B A D^{-}} d c p A \Delta v p s$ vs. parent, $\mathrm{t}=5$ & $* * * *$ & $<0.0001$ & Fig. $2 \mathrm{~A}$ \\
\hline$P_{B A D}-d c p A \triangle v p s$ vs. parent, $\mathrm{t}=6$ & $* * * *$ & $<0.0001$ & Fig. $2 \mathrm{~A}$ \\
\hline$m s h E^{*}$ vs. parent, $\mathrm{t}=0$ & ns & $>0.9999$ & Fig. 2B \\
\hline$m s h E^{*}$ vs. parent, $\mathrm{t}=1$ & ns & 0.4192 & Fig. 2B \\
\hline$m s h E^{*}$ vs. parent, $t=2$ & $* *$ & 0.0062 & Fig. 2B \\
\hline$m s h E^{*}$ vs. parent, $\mathrm{t}=3$ & $* * * *$ & $<0.0001$ & Fig. 2B \\
\hline$m s h E^{*}$ vs. parent, $\mathrm{t}=4$ & $* * * *$ & $<0.0001$ & Fig. 2B \\
\hline$m s h E^{*}$ vs. parent, $\mathrm{t}=5$ & $* * * *$ & $<0.0001$ & Fig. 2B \\
\hline$m s h E^{*}$ vs. parent, $\mathrm{t}=6$ & $* * * *$ & $<0.0001$ & Fig. 2B \\
\hline$\Delta c d p A, \Delta / a c Z:: c d p A$ vs. parent, time $=0$ & ns & $>0.9999$ & Fig. 4A \\
\hline$\Delta c d p A, \Delta / a c Z:: c d p A$ vs. parent, time $=1$ & ns & 0.9778 & Fig. 4A \\
\hline$\Delta c d p A, \Delta / a c Z:: c d p A$ vs. parent, time $=2$ & ns & 0.9309 & Fig. 4A \\
\hline$\Delta c d p A, \Delta / a c Z:: c d p A$ vs. parent, time $=3$ & ns & 0.8906 & Fig. 4A \\
\hline$\Delta c d p A, \Delta / a c Z:: c d p A$ vs. parent, time $=4$ & ns & 0.8244 & Fig. 4A \\
\hline$\Delta c d p A, \Delta / a c Z:: c d p A$ vs. parent, time $=5$ & ns & 0.8864 & Fig. 4A \\
\hline$\Delta c d p A, \Delta / a c Z:: c d p A$ vs. parent, time $=6$ & ns & 0.3401 & Fig. 4A \\
\hline$\Delta c d p A, \Delta / a c Z:: c d p A^{E C L \rightarrow A A A}$ vs. parent, time $=0$ & ns & $>0.9999$ & Fig. 4B \\
\hline$\Delta c d p A, \Delta / a c Z:: c d p A^{E C L \rightarrow A A A}$ vs. parent, time $=1$ & ns & 0.1993 & Fig. 4B \\
\hline$\Delta c d p A, \Delta / a c Z:: c d p A^{E C L \rightarrow A A A}$ vs. parent, time $=2$ & ** & 0.0032 & Fig. 4B \\
\hline$\Delta c d p A, \Delta / a c Z:: c d p A^{E C L \rightarrow A A A}$ vs. parent, time $=3$ & $* * * *$ & $<0.0001$ & Fig. 4B \\
\hline$\Delta c d p A, \Delta / a c Z:: c d p A^{E C L \rightarrow A A A}$ vs. parent, time $=4$ & $* * * *$ & $<0.0001$ & Fig. 4B \\
\hline$\Delta c d p A, \Delta / a c Z:: c d p A^{E C L \rightarrow A A A}$ vs. parent, time $=5$ & $* * * *$ & $<0.0001$ & Fig. 4B \\
\hline$\Delta c d p A, \Delta / a c Z:: c d p A^{E C L \rightarrow A A A}$ vs. parent, time $=6$ & $* * * *$ & $<0.0001$ & Fig. 4B \\
\hline parent, aerobic vs. microaerobic & ** & 0.0025 & Fig. 4C \\
\hline$m s h E^{*}$, aerobic vs. microaerobic & ** & 0.0088 & Fig. 4C \\
\hline$\Delta c d p A$, aerobic vs. microaerobic & ns & 0.2484 & Fig. 4C \\
\hline Total CdpA, aerobic vs. microaerobic & ns & 0.0773 & Fig. 4D \\
\hline Upper band, aerobic vs. microaerobic & ** & 0.0015 & Fig. 4D \\
\hline Lower band, aerobic vs. microaerobic & ns & 0.1172 & Fig. 4D \\
\hline$\Delta c d p A$ vs. $\triangle c d p A+$ NONOate & $* * * *$ & $<0.0001$ & Fig. 5B \\
\hline parent vs. $\Delta c d p A$, - NONOate & ns & 0.8180 & Fig. $5 \mathrm{C}$ \\
\hline parent vs. $\triangle c d p A,+$ NONOate & 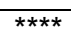 & $<0.0001$ & Fig. $5 \mathrm{C}$ \\
\hline$\Delta N a p$ vs. parent, time $=0$ & ns & $>0.9999$ & Fig. 5E \\
\hline$\Delta N a p$ vs. parent, time $=1$ & ns & 0.9221 & Fig. 5E \\
\hline$\Delta$ Nap vs. parent, time $=2$ & ns & 0.8995 & Fig. 5E \\
\hline$\Delta N a p$ vs. parent, time $=3$ & $\mathrm{~ns}$ & 0.8995 & Fig. 5E \\
\hline$\Delta N a p$ vs. parent, time $=4$ & ns & 0.9973 & Fig. 5E \\
\hline$\Delta$ Nap vs. parent, time $=5$ & ns & 0.9539 & Fig. 5E \\
\hline$\Delta$ Nap vs. parent, time $=6$ & ns & 0.9221 & Fig. 5E \\
\hline$\Delta v p s$ vs. parent, time $=0$ & ns & $>0.9999$ & Fig. S1C \\
\hline$\Delta v p s$ vs. parent, time $=1$ & ns & 0.9873 & Fig. S1C \\
\hline$\Delta v p s$ vs. parent, time $=2$ & ns & 0.8283 & Fig. S1C \\
\hline
\end{tabular}




\begin{tabular}{|c|c|c|c|}
\hline$\Delta v p s$ vs. parent, time $=3$ & $\mathrm{~ns}$ & 0.9873 & Fig. S1C \\
\hline$\Delta v p s$ vs. parent, time $=4$ & $\mathrm{~ns}$ & 0.9235 & Fig. S1C \\
\hline$\Delta v p s$ vs. parent, time $=5$ & $\mathrm{~ns}$ & 0.8283 & Fig. S1C \\
\hline$\Delta v p s$ vs. parent, time $=6$ & $\mathrm{~ns}$ & 0.3354 & Fig. S1C \\
\hline $\mathrm{P}_{\mathrm{BAD}}-c d g J$ vs. $\mathrm{P}_{\mathrm{BAD}}-c d g J m s h E^{*}$ & $* * * *$ & $<0.0001$ & Fig. S3A \\
\hline $\mathrm{P}_{\mathrm{BAD}-c d g J \text { vs. } \triangle \mathrm{MSHA}}$ & $* * * *$ & $<0.0001$ & Fig. S3A \\
\hline parent, aerobic vs. microaerobic & $* \star *$ & 0.0004 & Fig. S4A \\
\hline$m s h E^{*}$, aerobic vs. microaerobic & ns & 0.1874 & Fig. S4A \\
\hline$\Delta c d p A$, aerobic vs. microaerobic & $\mathrm{ns}$ & 0.9463 & Fig. S4A \\
\hline$\Delta c d p A$ vs. parent, time $=0$ & ns & $>0.9999$ & Fig. S5B \\
\hline$\Delta c d p A$ vs. parent, time $=1$ & $\mathrm{~ns}$ & 0.9139 & Fig. S5B \\
\hline$\Delta c d p A$ vs. parent, time $=2$ & ns & 0.1646 & Fig. S5B \\
\hline$\Delta c d p A$ vs. parent, time $=3$ & $* * * *$ & $<0.0001$ & Fig. S5B \\
\hline$\Delta c d p A$ vs. parent, time $=4$ & $* * * *$ & $<0.0001$ & Fig. S5B \\
\hline$\Delta c d p A$ vs. parent, time $=5$ & $* * * *$ & $<0.0001$ & Fig. S5B \\
\hline$\Delta c d p A$ vs. parent, time $=6$ & $* * * *$ & $<0.0001$ & Fig. S5B \\
\hline$\Delta c d p A$ vs. parent, time $=7$ & $* * * *$ & $<0.0001$ & Fig. S5B \\
\hline$\Delta c d p A$ vs. parent, time $=8$ & $* * * *$ & $<0.0001$ & Fig. S5B \\
\hline$\Delta c d p A$ vs. parent, time $=9$ & $* * * *$ & $<0.0001$ & Fig. S5B \\
\hline$\Delta c d p A$ vs. parent, time $=10$ & $* * * *$ & $<0.0001$ & Fig. S5B \\
\hline$\Delta c d p A$ vs. parent, time $=11$ & $* * * *$ & $<0.0001$ & Fig. S5B \\
\hline$\Delta c d p A$ vs. parent, time $=12$ & $* * * *$ & $<0.0001$ & Fig. S5B \\
\hline$\Delta c d p A, \Delta / a c Z:: c d p A-3 x F L A G$ vs. parent, time $=0$ & $\mathrm{~ns}$ & $>0.9999$ & Fig. S5C \\
\hline$\Delta c d p A, \Delta / a c Z:: c d p A-3 x F L A G$ vs. parent, time $=1$ & ns & 0.9953 & Fig. S5C \\
\hline$\Delta c d p A, \Delta / a c Z:: c d p A-3 x F L A G$ vs. parent, time $=2$ & $\mathrm{~ns}$ & 0.9990 & Fig. S5C \\
\hline$\Delta c d p A, \Delta / a c Z:: c d p A-3 x F L A G$ vs. parent, time $=3$ & ns & 0.9976 & Fig. S5C \\
\hline$\Delta c d p A, \Delta / a c Z:: c d p A-3 x F L A G$ vs. parent, time $=4$ & ns & 0.9151 & Fig. S5C \\
\hline$\Delta c d p A, \Delta / a c Z:: c d p A-3 x F L A G$ vs. parent, time $=5$ & ns & 0.9725 & Fig. S5C \\
\hline$\Delta c d p A, \Delta / a c Z:: c d p A-3 x F L A G$ vs. parent, time $=6$ & ns & 0.3426 & Fig. S5C \\
\hline
\end{tabular}

